\title{
Raman Lidar for Meteorological Observations, RALMO - Part 1: Instrument description
}

\author{
T. Dinoev ${ }^{1}$, V. Simeonov ${ }^{1}$, Y. Arshinov ${ }^{2}$, S. Bobrovnikov ${ }^{2}$, P. Ristori ${ }^{1,3}$, B. Calpini ${ }^{4}$, M. Parlange ${ }^{1}$, and H. van den \\ Bergh $^{5}$ \\ ${ }^{1}$ Laboratory of Environmental Fluid Mechanics and Hydrology (EFLUM), Ecole Polytechnique Fédérale de Lausanne \\ EPFL-ENAC, Station 2, 1015 Lausanne, Switzerland \\ ${ }^{2}$ V.E. Zuev Institute of Atmospheric Optics SB RAS1, Academician Zuev Square, Tomsk, 634021, Russia \\ ${ }^{3}$ División Lidar, CEILAP (UNIDEF-CITEDEF-MINDEF-CONICET), San Juan Bautista de La Salle 4397 (B1603ALO), \\ Villa Martelli, Buenos Aires, Argentina \\ ${ }^{4}$ Federal Office of Meteorology and Climatology MeteoSwiss, Atmospheric Data, P.O. Box 316, 1530 Payerne, Switzerland \\ ${ }^{5}$ Laboratory of Air and Soil Pollution, Ecole Polytechnique Fédérale de Lausanne EPFL, Station 6, \\ 1015 Lausanne, Switzerland
}

Correspondence to: V. B. Simeonov (valentin.simeonov@epfl.ch)

Received: 2 July 2012 - Published in Atmos. Meas. Tech. Discuss.: 20 September 2012

Revised: 19 April 2013 - Accepted: 22 April 2013 - Published: 22 May 2013

\begin{abstract}
A new Raman lidar for unattended, round-theclock measurement of vertical water vapor profiles for operational use by the MeteoSwiss has been developed during the past years by the Swiss Federal Institute of Technology, Lausanne. The lidar uses narrow field-of-view, narrowband configuration, a UV laser, and four $30 \mathrm{~cm}$ in diameter mirrors, fiber-coupled to a grating polychromator. The optical design allows water vapor retrieval from the incomplete overlap region without instrument-specific rangedependent corrections. The daytime vertical range covers the mid-troposphere, whereas the nighttime range extends to the tropopause. The near range coverage is extended down to $100 \mathrm{~m}$ AGL by the use of an additional fiber in one of the telescopes. This paper describes the system layout and technical realization. Day- and nighttime lidar profiles compared to Vaisala RS92 and Snow White ${ }^{\circledR}$ profiles and a six-day continuous observation are presented as an illustration of the lidar measurement capability.
\end{abstract}

\section{Introduction}

Water vapor plays a fundamental role in the radiative energy transfer, hydrological cycle, and atmospheric chemistry processes that determine weather and climate. It influences the radiative budget of the planet both directly and through coupling with clouds. Because of its strong absorption and emission bands, especially in the infrared, and because of its abundance, water vapor is the most significant greenhouse gas, and in this sense the most important in establishing the Earth's climate.

Water vapor distribution is strongly affected by atmospheric dynamics, but in turn it also influences atmospheric circulation and temperature structure by condensationevaporation processes. The water evaporation-condensation cycle is an important mechanism for transferring heat energy from the Earth's surface to its atmosphere and in moving heat around the Earth. The large latent energy associated with the water phase changes significantly affects the meridional energy balance and the vertical stability of the atmosphere as well as the structure and evolution of storm systems, not only in the boundary layer (Normand, 1938) but also in the middle and upper troposphere (Peppler, 1989; Sinha and Harries, 1995; Arnold, 2008). 
Because of its essential role in the atmospheric processes, the water vapor spatial distribution and its temporal evolution are two of the most important parameters in global and regional numerical weather prediction (NWP) models. To improve near-surface weather predictions, and to better simulate the evolution of local severe weather events in complex terrains (Wulfmeyer et al., 2008), the time and space resolution of the NWP models, used by the meteorological services, is currently being increased (Calpini et al., 2011). The vertical water vapor profiles assimilated by these models are mainly acquired by twice-a-day radiosonde observations which have insufficient time resolution to resolve fast running meteorological phenomena. In addition, radiosonde measurements suffer from systematic errors that are difficult to correct and from essential sonde-to-sonde variations not only between instruments from different producers and operational principles, but even between instruments of the same batch (Nash et al., 2011). Ground-based microwave radiometers (Solheim, 1998 and references therein) and Fourier transform infrared radiometers (Schneider and Hase, 2009 and references therein) provide humidity profiles with sufficient time resolution, but with rather low vertical resolution, to resolve the spatial variability of water vapor in the low troposphere. Therefore, national meteorological services need a new type of autonomous, continuously operated (24-7-365) instruments for near real-time, high spatial resolution observations of the tropospheric water vapor field.

Lidar (light detection and ranging) is one of the techniques able to resolve the high temporal and spatial variability of tropospheric water vapor. The advances of the last decades in the field of laser technology and improved lidar design make lidars suitable for operational use in meteorological services. Two lidar techniques, DIAL and Raman, are used for water vapor measurements.

The DIAL principle exploits the difference in atmospheric extinction due to water vapor absorption at two closelyspaced, near-IR wavelengths. Provided accurate knowledge of water vapor absorption cross section is available, DIAL does not need other external references for correct measurements and in this sense is considered "self-calibrating". A DIAL system has the potential to perform daytime observations with high temporal resolution but limited altitude range $(2-3 \mathrm{~km})$ when operated from low-altitude, groundbased sites because the humid air in the boundary layer significantly attenuates the laser beam (Wulfmeyer and Bosenberg, 1998; Böosenberg and Linne, 2006). DIAL systems use tunable laser sources, which are more complicated, expensive (Wulfmeyer, 1998; Bruneau, 2001; Browell et al., 1998) and less reliable than the lasers used in Raman lidars. This, together with the complicated data treatment (Bösenberg, 1998), is another obstacle for implementing DIAL as an operational, ground-based instrument for meteorology. This technique, however, is well suited for airborne and satellite profiling (Wirth et al., 2009; Bruneau et al., 2001; Browell et al., 1998).
The Raman lidar technique exploits Raman scattering from water vapor and nitrogen molecules to derive a profile of water vapor mixing ratio (Cooney, 1970; Melfy, 1972). At present, the nighttime distance range can reach up to the lower stratosphere but at daytime the range is limited to the middle troposphere because the weak Raman signals are detected in the presence of intensive daylight background. A Raman lidar requires calibration either against a reference instrument or by absolute radiometric calibration of the lidar optics, provided accurate Raman cross sections are available. Contrary to a DIAL, a Raman lidar does not require tunable laser source with specific and highly stabilized wavelengths. Furthermore, the Raman data-treatment algorithm is significantly simpler than the DIAL algorithm, and allows data retrieval from the incomplete overlap region. Because of all these advantages and because of the higher reliability, Raman lidars are preferred for operational use in meteorology from ground-based stations (Goldsmith et al., 1998; Engelbart et al., 2006; Reichardt et al., 2012; Simeonov et al., 2010; Appituley et al., 2009).

Raman lidars have been used for high resolution vertical profiling of water vapor within the troposphere since the early 1970s. Most of the measurements were performed for research purposes and at nighttime (Whiteman, 1992; Ansmann et al., 1992; Vaughan et al., 1988; Balin et al., 2004). First daytime measurements were possible using laser wavelength shorter than $300 \mathrm{~nm}$ because at these wavelengths the solar light is absorbed by stratospheric ozone (Renault et al., 1980; Cooney et al., 1985). The vertical range of such lidars is, however, limited to about $2 \mathrm{~km}$, mainly due to tropospheric ozone absorption. The use of a narrow field-of-view (NFOV), narrowband (NB) receiver allows operation at visible and near UV wavelengths, resulting in the extension of the operational range up to the mid troposphere (Goldsmith et al., 1998).

The successful long-term operation of the first automated NFOV NB lidar-CART (Goldsmith et al., 1998) - motivated the German (Engelbart et al., 2006; Reichardt et al., 2012), the Swiss (Dinoev et al., 2006; Simeonov et al., 2010) and the Dutch (Appituley et al., 2009) meteorological services to establish programs aiming at the development of operational water vapor lidars.

Here we present the instrument description and some illustrative results from the Swiss RAman Lidar for Meteorological Observations (RALMO). The instrument is dedicated to operational meteorology, model validation, climatological studies as well as ground truthing of satellite data. The lidar was specially designed to satisfy the essentials for operational meteorology and climatology requirements of long-term data homogeneity, accuracy and precision. To attain these goals, special attention was paid to achieving long-term instrument stability and eliminating the need for instrument-specific range-dependent corrections.

RALMO was developed and built by the Swiss Federal Institute of Technology, Lausanne (Ecole Polytechnique 
Fédérale de Lausanne-EPFL) as a co-funded project with Swiss Meteorological Service (MeteoSwiss) and supported by the Swiss National Foundation.

Since August 2008, the lidar has been operated at the Aerological station of Payerne $\left(46^{\circ} 48^{\prime} \mathrm{N}, 6^{\circ} 56^{\prime} \mathrm{E}\right.$, $492 \mathrm{~m}$ a.s.1.) by MeteoSwiss with the support of EPFL. During this period RALMO demonstrated long-term system stability, data homogeneity and high technical availability, as presented in the companion paper (Brocard et al., 2013). The lidar deployment in Payerne observatory increases the station capacity for monitoring tropospheric water vapor profiles and reinforces its role as a GRUAN station and a CIMO test-bed.

The article is structured as follows: the physical principles of Raman remote sensing of water vapor are summarized in Sect. 2. A detailed description of the instrument follows in Sect. 3, and the data processing and calibration, as well as example results are presented in Sect. 4.

\section{Theory}

\subsection{Lidar equation}

The operation is based on the well-known Raman lidar principle where a humidity profile is derived from the water vapor and nitrogen Raman components of atmospheric laser backscatter (Cooney, 1970; Melfi, 1972). In a single scattering approximation, the power of the Raman lidar signal per pulse $S_{x}(z)$ from altitude $z$ is

$S_{x}(z)=E \frac{\mathrm{AO}_{x}(z)}{z^{2}} \frac{c}{2} \kappa_{x} \sigma_{x}^{\pi}(\lambda, T) N_{x}(z) \Delta t_{x}^{\mathrm{aer}}(z)$

$\Delta t_{x}^{\mathrm{mol}}(z)+S_{\mathrm{B} x} \kappa_{x}$

where $E$ is the laser energy per pulse, $A$ is the telescope surface, $O_{x}(z)$ is the overlap function, $\kappa_{x}$ is the total efficiency of the lidar receiver for the respective Raman wavelength and $\sigma_{x}^{\pi}(\lambda, T)$ is the Raman cross section of species $x$ with number density $N_{x}(z)$, where $T$ is the temperature of the probed volume. The attenuation of the laser beam and the Raman backscattered light due to aerosol scattering and absorption is accounted for in $\Delta t_{x}^{\text {aer }}(z)$, and $\Delta t_{x}^{\mathrm{mol}}$ is the molecular attenuation. $S_{\mathrm{B} x}$ is the power of the sky background (Measures, 1992):

$S_{\mathrm{B} x}=\Phi_{x}(\lambda) A \Omega \Delta \lambda_{x}$

where $\phi_{x}(\lambda)$ is the zenith sky spectral radiance, $\Omega$ is the fieldof-view of the telescope, expressed as a solid angle, and $\Delta \lambda_{x}$ is the spectral transmission bandwidth (FWHM) of the detection channel. In daytime conditions, the lidar receiver detects considerable amount of diffuse sky light, which influences the daytime performance of the lidar by significantly reducing the signal-to-noise ratio (SNR) of the Raman signals. The daylight influence can be reduced using a narrow field-ofview receiver and a polychromator with narrowband, which isolates only the $\mathrm{Q}$ branch of the ro-vibrational spectra of the signals (Goldsmith et al., 1998).

The optical signal $S_{x}(z)$ is converted to electrical signal by a photomultiplier, operated in photon-counting or (and) analog mode. The photon-counting rate $P_{x}(z)$, is related to $S_{x}(z)$ as

$P_{x}(z)=\frac{S_{x}(z)}{h v_{x}} \varepsilon_{x}$

where $h$ is the Planck constant, $v_{x}$ is the frequency of the incident photon, and $\varepsilon_{x}$ is the detection efficiency of the photomultiplier. Note that Eq. (3) does not take into account pulse pileup (saturation). The average analog signal in volts can be presented as

$A_{x}(z)=\frac{S_{x}(z)}{h v_{x}} \varepsilon_{x} e g R$

where $e$ is the electron charge, $g$ is the photomultiplier gain, and $R$ is the load impedance. In the following discussions we will use photon-counting signals. This does not limit the generality of the discussion and is justified by the fact that in the predominant part of the Raman lidars, including the one presented here, the detection is carried out in a photoncounting mode and analog detection is used only when signal desaturation is not possible.

A profile of the water vapor mixing ratio $q(z)$ is derived from the ratio of the water vapor to nitrogen lidar signals as

$q(z)=n C_{\mathrm{L}}(z) \frac{\overline{P_{\mathrm{H}_{2} \mathrm{O}}(z)}}{\overline{P_{\mathrm{N}_{2}}(z)}} \Delta \tau(z)$

where the signals $\overline{P_{\mathrm{H}_{2} \mathrm{O}}(z)}$ and $\overline{P_{\mathrm{N}_{2}}(z)}$ are backgroundcorrected and averaged over time and range to reduce the statistical error. $C_{\mathrm{L}}(z)$ is the lidar calibration function and the coefficient $n=0.485$ converts the obtained through lidar measurements water vapor to nitrogen number density mixing ratio to water vapor to dry-air mass mixing ratio, $\Delta \tau(z)$ is the one-way differential atmospheric transmission at water vapor and nitrogen Raman wavelengths and depends on the profiles of the aerosol $\Delta \alpha^{\mathrm{a}}(z)=\alpha_{\mathrm{H}_{2} \mathrm{O}}^{\mathrm{a}}(z)-\alpha_{\mathrm{N}_{2}}^{\mathrm{a}}(z)$ and molecular $\Delta \alpha^{\mathrm{m}}(z)=\alpha_{\mathrm{H}_{2} \mathrm{O}}^{\mathrm{m}}(z)-\alpha_{\mathrm{N}_{2}}^{\mathrm{m}}(z)$ differential extinctions as

$\Delta \tau(z)=\exp \left\{-\int_{0}^{z}\left[\Delta \alpha^{\mathrm{m}}\left(z^{\prime}\right)+\Delta \alpha^{\mathrm{a}}\left(z^{\prime}\right)\right] \mathrm{d} z^{\prime}.\right\}$

The molecular extinction can be calculated from atmospheric pressure and temperature profiles, measured by balloon sounding or derived from an atmospheric model (usually US Standard Atmosphere). The aerosol contribution is below $10 \%$ even for hazy conditions (Whiteman, 1992; Whiteman et al., 2001) and usually can be neglected. The aerosol extinction profiles can be obtained from Raman lidar measurements if available (Ansmann et al., 1992). 


\subsection{Lidar calibration function and related systematic errors}

The calibration function $C_{\mathrm{L}}(z)$ is a prime factor defining the measurement accuracy, so any imprecision in its determination leads to important systematic errors. Additional systematic errors arise in signal acquisition. We shall discuss both sources in the following section. Technical solutions for reduction of these systematic errors and estimations of the residual errors are discussed in the instrument description sections below.

The lidar calibration function $C_{\mathrm{L}}$ converts the measured $\frac{\overline{P_{\mathrm{H}_{2} \mathrm{O}}(z)}}{\overline{P_{\mathrm{N}_{2}}(z)}}$ signal ratio to $\mathrm{H}_{2} \mathrm{O} / \mathrm{N}_{2}$ number density mixing ratio. It depends on instrumental parameters as well as on the respective Raman cross sections and can be expressed as follows:

$C_{\mathrm{L}}(z, \lambda, T)=\frac{O_{\mathrm{N}_{2}}(z)}{O_{\mathrm{H}_{2} \mathrm{O}}(z)} \frac{t_{\mathrm{N}_{2}}}{t_{\mathrm{H}_{2} \mathrm{O}}} \frac{\varepsilon_{\mathrm{N}_{2}}}{\varepsilon_{\mathrm{H}_{2} \mathrm{O}}} \frac{\int \sigma_{\mathrm{N}_{2}}^{\pi}(\lambda, T) I_{\mathrm{N}_{2}}(\lambda) \mathrm{d} \lambda}{\int \sigma_{\mathrm{H}_{2} \mathrm{O}}(\lambda, T) I_{\mathrm{H}_{2} \mathrm{O}}(\lambda) \mathrm{d} \lambda}$

where $t_{x}$ is the total, wavelength-independent optical transmission of the detection channel $x$ (including all the optics from the telescope input to the polychromator exit), $I_{x}(\lambda) \in[0,1]$ is the instrumental function of the polychromator and $\varepsilon_{x}$ is the photodetector detection efficiency.

The calibration function can be determined directly from Eq. (7) if all parameters are known (Vaughan et al., 1988; Sherlock et al., 1999) but the uncertainties of the Raman cross sections and of the instrumental parameters lead to unacceptably high calibration errors $(10-15 \%)$. Therefore experimental calibration against a reference instrument, such as a balloon-borne sonde or microwave radiometer, is commonly used. In this approach $C_{\mathrm{L}}$ is represented as a product of a range-independent part, referred to as calibration constant, and two range-dependent correction functions named usually "overlap" and "temperature" corrections (Whiteman, 1992, 2003; Whiteman et al., 2012; Goldsmith et al., 1998). The overall systematic error of the calibration function is hence a sum of the systematic errors of the calibration constant and the correction functions, plus errors not accounted for by "overlap" and "temperature" corrections. The accuracy of the calibration constant depends on the accuracy of the reference instrument and the calibration procedure and currently allows achieving uncertainty on the order of $5 \%$ (Turner et al., 2002).

The overlap correction (Vaughan et al., 1988; Whiteman, 1992) compensates for instrumental imperfections of the lidar receiver. The overlap error is often the dominating rangedependent systematic error, and its magnitude strongly depends on the lidar design but often is above $10 \%$ (Turner and Goldsmith, 1999). The overlap correction function is typically obtained as a ratio of two nitrogen signals detected in water vapor and nitrogen channels while using identical nitrogen filters. There are, however, important drawbacks to this approach. First, the accuracy of the correction obviously depends on the level of identity of the two filters. Second, the correction function depends on the lidar alignment, such that it may require frequent examination and corrections, which is not acceptable for an instrument operated in a meteorological network. Finally the error remaining after the application of the "overlap" correction could still be relatively high and range dependent (Ferrare et al., 2004). Given these drawbacks, and especially considering the requirement for continuous operation with minimal operator intervention for our lidar as part of the Swiss meteorological network, we looked for solution which eliminates the need of overlap correction.

To find such a solution, the origins of range-dependence of the lidar calibration function $C_{\mathrm{L}}$ need to be examined. As can be seen from Eq. (7), $C_{\mathrm{L}}$ depends directly on the range only through the overlap functions and only in the incomplete overlap region. Since the telescopes of most, if not all, Raman lidars are of a reflective type, they are virtually free of chromatic aberrations. As a result, the two overlap functions, defined at the telescope output aperture, are identical and cancel out because the two Raman signals are produced by the same laser beam. Hence, the reason for the range dependence of $C_{\mathrm{L}}$ and related systematic errors is the indirect range-dependence of the remaining terms.

There are several reasons for this indirect range dependence. They can be sorted into two groups: the first group includes errors due to optical imperfections of the lidar receiver; the second group comprises problems induced by the photodetectors and the acquisition system.

Among the optical imperfections of the lidar receiver, range-dependent variations of the transmission, reflection or polarization properties of the optical elements of the receiver are common, and typically have the highest quantitative impact. They are induced by range-related variations of the incidence angle or the position (Whiteman et al., 2012) of the optical beams on the surface of the receiver optical elements. These effects are stronger for lidars using dichroic beam-splitters and interference filters for their polychromator, and also for lidars with an open-space link between the telescope and the polychromator. Employing a diffraction grating-based polychromator fiber coupled to the telescope allow for reducing the errors induced by these rangedependent optical imperfections of the lidar receiver to negligible level. Other optical sources of range-dependent systematic errors are chromatic aberrations, change in size and vignetting of the optical beams after the telescope. These errors, however, are relatively easy to eliminate through appropriate optical design.

A range dependence of $C_{\mathrm{L}}$ and related systematic errors caused by the photodetector imperfections can arise from spatial inhomogeneity of the active surfaces of the photomultipliers (Simeonov et al., 1999), photomultiplier nonlinearities, saturation, and signal-induced noise.

The spatial inhomogeneity is specific for each type and each individual photomultiplier. The variations in sensitivity over the photocathode surface may reach several hundred 
percent (Simeonov et al., 1999). The magnitude of the mixing ratio error induced by the inhomogeneity of the photomultipliers depends on the lidar design. In general, lidars with free-space link are more affected compared to those with fiber connection between the telescope and the polychromator because of the range-dependent displacement of the image of the probed volume on the active area of the detector. A solution to the problem, known from astronomy, is the use of a field lens (e.g. Fabry and Buisson, 1921).

Photomultiplier nonlinearity and the signal-induced noise are the other systematic error sources related to photon detection. Since signal detection in most of the Raman lidars is carried out in photon-counting mode, the deviation from linearity is mostly due to saturation (pulse pileup). The magnitude of the induced systematic error on a Raman signal depends on the photomultiplier and the counter parameters but easily can exceed $10 \%$ (Whiteman, 2003). Desaturation techniques are used to correct the signal nonlinearities (e.g. Ingle and Crouch, 1972; Donovan et al., 1993). Further linearity improvement of the desaturated signals is achieved by constraining the desaturated signal to simultaneously recorded analog signals converted to photon counts (Newsom et al., 2009). The use of analog signals not only improves the linearity but also extends the dynamic range. The signal induced noise affects the water vapor retrieval at higher altitudes and is usually more pronounced in glass-bulb PMTs. Our tests show that the "metal channel" type PMTs of Hamamatsu are practically free from signal induced noise.

The temperature correction compensates for temperature(and hence range-) dependent variations of the Raman cross sections. The relative impact of the temperature sensitivity is more pronounced in the upper troposphere because of temperatures significantly lower than those at which the calibration constant is usually derived. The temperature-sensitive parts of $C_{\mathrm{L}}$ are

$f_{x}=\int \sigma_{x}^{\pi}(\lambda, T) I_{x}(\lambda) \mathrm{d} \lambda$.

Due to the structure of the water molecule, the Raman cross section of water vapor is more sensitive to temperature and hence dominates the systematic error induced by the temperature variations. The magnitude of this error can vary from above $10 \%$ to below $0.5 \%$ (see Fig. 8) for a temperature range of $100^{\circ} \mathrm{C}$, depending on the choice of the central wavelength and bandwidth of the polychromator instrumental function (Whiteman, 2003). The explicit correction for the temperature dependence, as suggested in (Whiteman, 2003), is complicated in practice: the atmospheric temperature profile may not be available with the required precision, and data treatment becomes more involved. Furthermore, additional systematic errors can arise due to uncertainties in the input parameters, namely the Raman cross sections at different temperatures or spectrometer transmission function. As will be shown in Sect. 3.2.1, the temperature dependence of $C_{\mathrm{L}}$ can be reduced to around $1 \%$ by optimization of the band- width and the central wavelength of the instrumental functions. In this way, the need for a temperature correction can be avoided altogether.

There are also additive errors that are not accounted for by the lidar calibration function and its corrections. Insufficient suppression of the excitation radiation, optics and air fluorescence, and cross talk between Raman signals originating from different atmospheric species are systematic error sources well known from Raman spectroscopy. Of particular concern is insufficient suppression of the laser excitation light, which is backscattered elastically from the atmosphere; suppression levels of $10^{8}-10^{10}$ are required for typical tropospheric measurements, but higher levels may be required at higher altitudes because of lower water content. Fluorescence, both from optical elements of the receiver and the atmosphere itself, as well as undesired cross talk between the Raman channels are an important concern for measurements in the upper troposphere, where the water vapor concentration and hence the signal in the water channel is low. Blocking the elastic light as early as possible, proper selection of the material of the optical elements and avoiding contamination of the optics with organic materials are usually sufficient to reduce this error to negligible levels. Another reason for the range dependence, not included in Eq. (5) and pronounced mostly in the incomplete overlap region, is the time difference between the two Raman signals. Such a difference could be due to a difference in the optical paths, different time responses of the detectors and/or the acquisition system, or differences in the triggering of the acquisition system channels.

\section{Instrument description}

To satisfy the requirements for operational use in a meteorological network, a water vapor lidar has to meet a number of criteria, the most important of which are listed below: daytime and nighttime measurements covering the middle and the high troposphere, respectively; accuracy and precision of the measured parameters; traceability of the measurement; near real-time data availability; long-term data consistency; long-term system stability; autonomous operation; minimal maintenance by a technician; and eye safety. All these requirements were taken into account during the design phase of the lidar construction. The specific design features of the lidar are summarized in the following paragraphs and presented in detail in the next sections.

The lidar uses a narrowband, narrow field-of-view configuration and an excitation laser operating at $355 \mathrm{~nm}$ in order to ensure daytime operation. The receiver telescope consists of four, $30 \mathrm{~cm}$ in diameter mirrors, fiber-coupled to a grating polychromator. Extension of the operational range in the lower part of the profile down to $100 \mathrm{~m}$ is achieved by using incomplete overlap signals and two fibers in one of the telescopes. The second fiber is collecting signals from 
Table 1. System parameters.

\begin{tabular}{ll}
\hline Transmitter & Receiver \\
\hline Nd:YAG laser - third harmonic: & Four fiber coupled \\
Wavelength: $354.7 \mathrm{~nm}$ & parabolic mirrors: \\
Spectral line width: $0.7 \mathrm{~cm}^{-1}$ & Focal length: $1 \mathrm{~m}$ \\
Rep. rate: $30 \mathrm{~Hz}$ & Diameter: $0.3 \mathrm{~m}$ \\
Pulse energy: $300 \mathrm{~mJ}$ & Axial displacement: $235 \mathrm{~mm}$ \\
Pulse duration: $8 \mathrm{~ns}$ & (to expander axis) \\
Beam expander - Galilean type: & FOV: $3 \times 0.20$ and $1 \times 0.22 \mathrm{mrad}$ \\
Expansion ratio $15 \times$ & Polychromator - Diffraction \\
Transmitted beam: & grating based: \\
Divergence: & Bandwidth $(\mathrm{FWHM):} 0.33 \mathrm{~nm}$ \\
calculated $0.06 \mathrm{mrad}$ & ( $\mathrm{H}_{2} \mathrm{O}$ and $\left.\mathrm{N}_{2}\right)$ \\
measured $0.09 \pm 0.02 \mathrm{mrad}$ & Central wavelength $\mathrm{H}_{2} \mathrm{O}$ \\
Diameter: $140 \mathrm{~mm}$ & $407.45 \mathrm{~nm}$ \\
& $\mathrm{~N}_{2} 386.7 \mathrm{~nm}$ \\
& ${\left.\text { Efficiency: } 33 \% \text { (peak at } \mathrm{H}_{2} \mathrm{O}\right)}$ \\
& Photodetectors $($ Hamamatsu) \\
& $\mathrm{H}_{2} \mathrm{O}$ R7600U-200 \\
& $\mathrm{N}_{2}$ and $\mathrm{O}_{2} \mathrm{H} 6780$ \\
\hline
\end{tabular}

distances close to the lidar. The need for range-dependent corrections is eliminated by the careful design of the receiver, which removes the range dependence of the instrumental part of the lidar calibration constant (Eq. 7). Elimination of the range-dependent corrections not only simplifies the data treatment and calibration but also allows accurate humidity measurements for cases of transmitter-receiver misalignment, but at the price of reduced distance range (or precision). To achieve long-term data consistency, a grating-based (instead of interference-filter-based) polychromator is used. The compact and rigid mechanical design of the lidar, together with the fiber-optic connection between the lidar telescope and the polychromator, ensures long-term alignment stability and eliminates the need for frequent transmitterreceiver alignments.

Figure 1 shows the general optical layout of the lidar, whereas the main lidar parameters are summarized in Table 1 and the details are given in the following sections. The mechanical setup of the lidar and a photo of the telescope are shown in Figs. 2 and 3, respectively. Two computers ensure the automatic operation of the lidar. The first computer controls the lidar hardware and data acquisition, whereas the second one is used for automated data treatment and data transfer. The lidar is installed in a dedicated, clean compartment of an air-conditioned cabin. Four tilted windows, installed above the telescope mirrors, and one horizontal window above the beam expander ensure the weather tightness of the cabin. The cabin is located in a hangar equipped with a sliding roof hatch. The lidar requires only a power supply and a LAN connection for data upload.

\subsection{Transmitter}

The transmitter is based on a frequency tripled, Q-switched Nd:YAG laser (Continuum Powerlite II 9030), supplying up

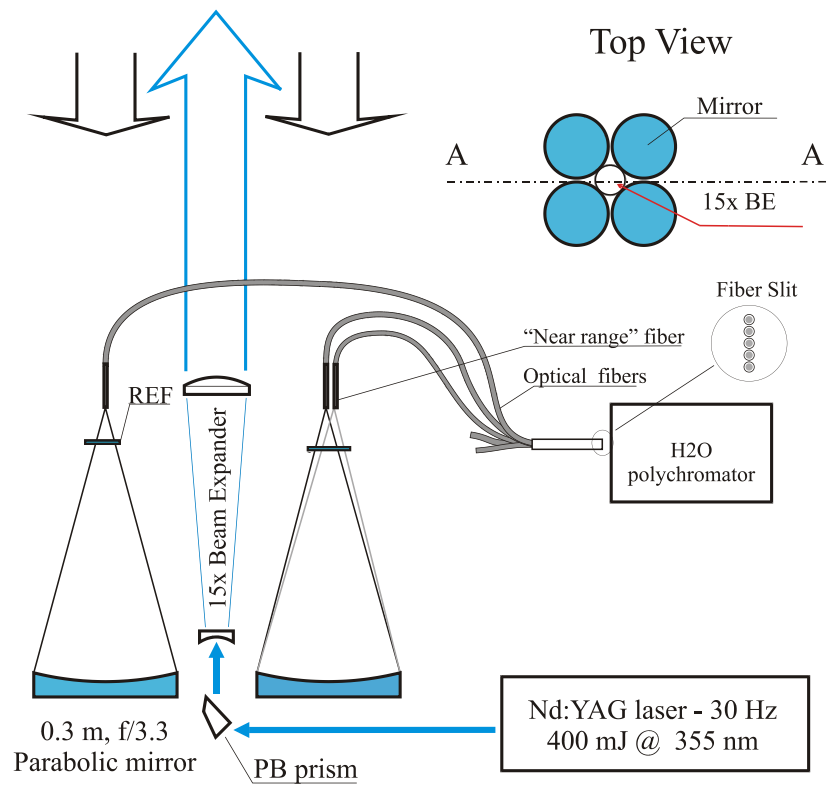

Fig. 1. Lidar optical scheme: A $15 \times$ beam expander is centered between four $30 \mathrm{~cm}$ in diameter, $\mathrm{f} / 3.33$ parabolic mirrors as illustrated by the top view shown in the upper right corner. The optical scheme is a cross section along the line A-A of the top view, therefore only two of the telescope mirrors can be seen; REF - Razor edge filter $\left(\right.$ Semrock $\left.^{\circledR}\right)$; PB - Pellin-Broca prism; PMT - photomultiplier.

to $400 \mathrm{~mJ}$ energy per pulse at $354.7 \mathrm{~nm}$, at $30 \mathrm{~Hz}$ repetition rate with $8 \mathrm{~ns}$ pulse duration. To extend the flash-lamps lifetime from 20 to approximately 60 million shots, the laser is operated at $300 \mathrm{~mJ}$ energy per pulse. The laser was additionally equipped with an energy meter for monitoring the output energy at the third harmonic.

The laser beam is expanded, firstly to reduce the beam divergence needed for daytime operation, and secondly to achieve the required eye-safe operation irradiance decrease. The beam expander is a $15 \times$ Galilean type consisting of two fused-silica lenses: a negative meniscus lens at the input and an aspheric, plano-convex lens at the output (Institute of Atmospheric Optics, Tomsk, Russia). Both lenses are AR coated (SLS Optics Ltd.) for improved expander efficiency. The beam from the laser is directed to the expander input with a fused-silica Pellin-Broca prism. The input and output surfaces of the prism are oriented at Brewster angle, and the laser polarization is rotated with a multiple-order, halfwave plate, installed before the prism to minimize the Fresnel losses on the prism surfaces. The beam steering before the expander reduces the degree of potential beam versus receiver misalignment, caused by laser pointing instability, laser misalignment or displacement of the laser versus the expander, thus improving the alignment stability of the lidar. The use of a prism instead of a dielectric mirror improves the reliability of the lidar and prevents back-reflected from the expander IR radiation from reaching the laser. 


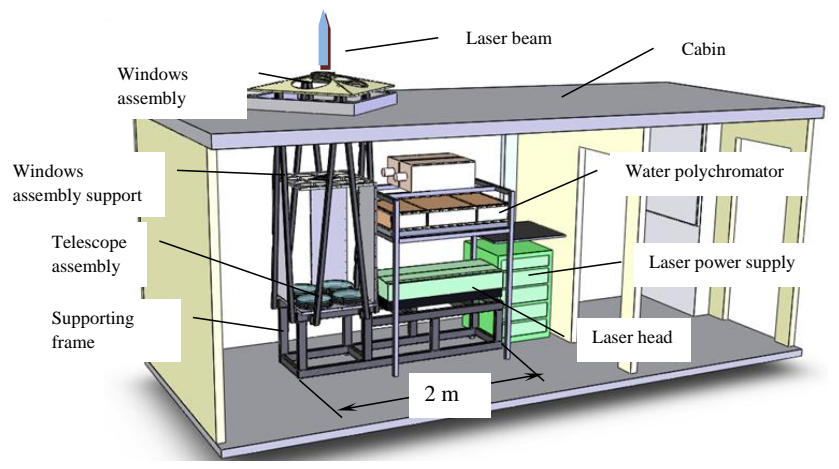

Fig. 2. Mechanical setup of the lidar: a support frame welded from square stainless steel tubing holds the telescope assembly, the laser head, and a protective window support; the lidar polychromator is mechanically separated from the telescopes using fiber coupling (not shown in the figure).

Ray tracing analysis of the beam expander, taking into account the specified lens aberrations, predicts a reduction of the specified by the laser producer $0.5 \mathrm{mrad}$ beam divergence to approximately $0.06 \mathrm{mrad}$ (full angle), and expansion of the beam diameter from $9 \mathrm{~mm}$ to approximately $140 \mathrm{~mm}$. The measured beam divergence shows values of $0.090 \pm 0.020 \mathrm{mrad}$. The difference between the modeled and measured output divergence can be explained by unaccounted lens aberrations or beam expander misalignment. According to the IEC 60825-1 standard, "Safety of laser products", the expanded beam is eye- and skin safe for exposure times shorter than $5 \mathrm{~s}$ for altitudes below $400 \mathrm{~m}$, whereas above $400 \mathrm{~m}$ the safe exposure time increases.

\subsection{Receiver}

\subsubsection{Telescope assembly}

The lidar receiver uses four, $30 \mathrm{~cm}$ in diameter, $\mathrm{f} / 3.33$ parabolic mirrors (Institute of Atmospheric Optics, Tomsk, Russia) for collecting the backscattered light. Short focal length mirrors were chosen because they allow coupling between the telescope and the polychromator with small corediameter fibers, and compact telescope design. Furthermore, the comparatively small diameter of the mirrors makes possible the use of dielectric coatings with reflectivity better than $99 \%$ for the wavelength range $375-410 \mathrm{~nm}$ and AR coated protective windows (both by SLS Optics Ltd.). The mirrors are tightly arranged around the beam expander (Figs. 1, 2 and 3 ) in a robust assembly with a cross section of $0.7 \times 0.7 \mathrm{~m}$ and height of $1 \mathrm{~m}$. The telescope assembly and the laser head are mounted on a frame welded from square stainless steel tubing. The frame is fixed to the cabin floor with vibration isolators for improving the lidar alignment reliability. The rigid and compact transmitter-receiver design reduces the possibility of mechanical and thermal lidar misalignment. Multimode 0.22 NA, UV-enhanced (Ceram Optec ${ }^{\circledR}$ ) fused silica

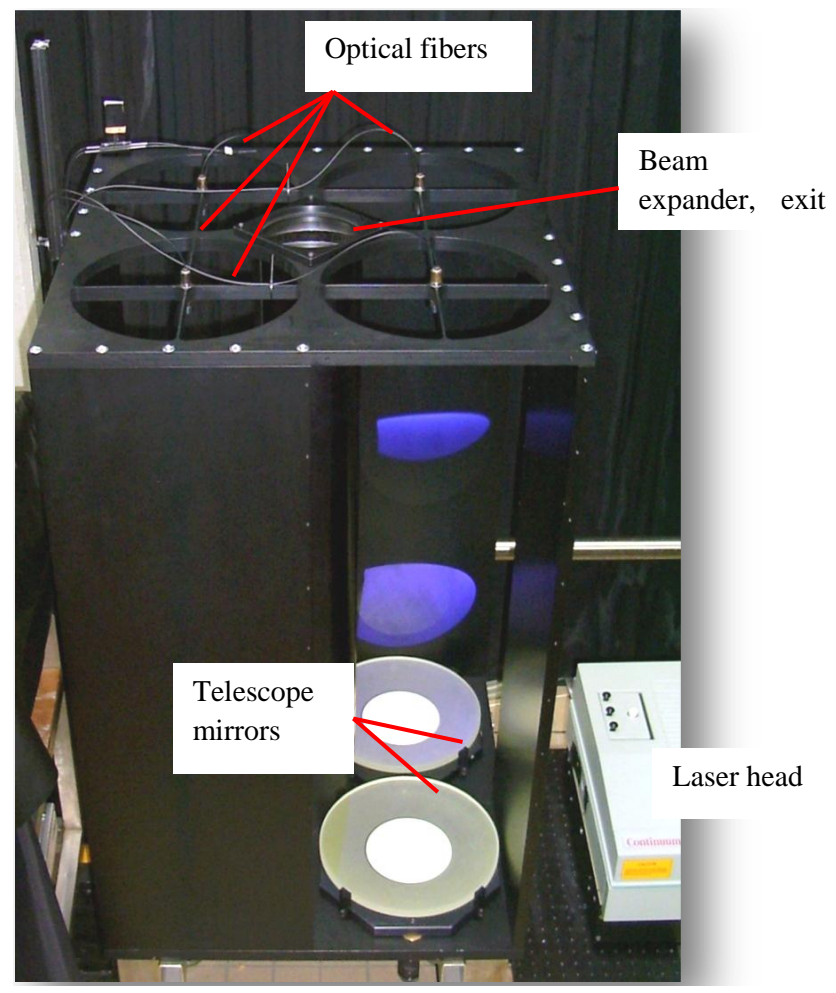

Fig. 3. Photograph of the telescope assembly taken before installation of the windows assembly support. Two of the four telescope mirrors are seen.

fibers, installed near the mirrors focal planes, transmit the collected light to the entrance of the lidar polychromator. The fibers core diameter of $0.2 \mathrm{~mm}$ defines a $0.2 \mathrm{mrad} F O V$ of the receiver. Long-pass, edge filters (Semrock ${ }^{\circledR}$ REF 364) with cutoff wavelength of $363.8 \mathrm{~nm}$ and transmission of $10^{-6}$ at $354.7 \mathrm{~nm}$ are installed in front of the optical fibers. The filters prevent the strong elastic backscatter light from entering the fibers, thus eliminating any possible fiber fluorescence and consequent artifacts. The filters contribute also to the total rejection of the elastic light in the Raman channels.

The receiver is aligned by tilting the individual parabolic mirrors and displacing the fiber ends towards and away from the mirrors. Kinematic mounts with differential screws are used to tilt each mirror axis within and across a plane defined by the mirror center and the expander axis. The axial displacement of the fibers is performed by holders equipped with differential screws. To detect potential signal loss in the far range, we use the product of the overlap function with the two-way aerosol transmission profile, derived from the nitrogen Raman signal.

The full overlap of the receiver is reached at approximately $5 \mathrm{~km}$ for fibers positioned at $0.1 \mathrm{~mm}$ behind the focus (focusing at $10 \mathrm{~km}$ ) and mirror axes parallel to the beam expander axe. To increase the signal level and improve the signal-tonoise ratio below $5 \mathrm{~km}$, we tilt the mirrors in the direction of 


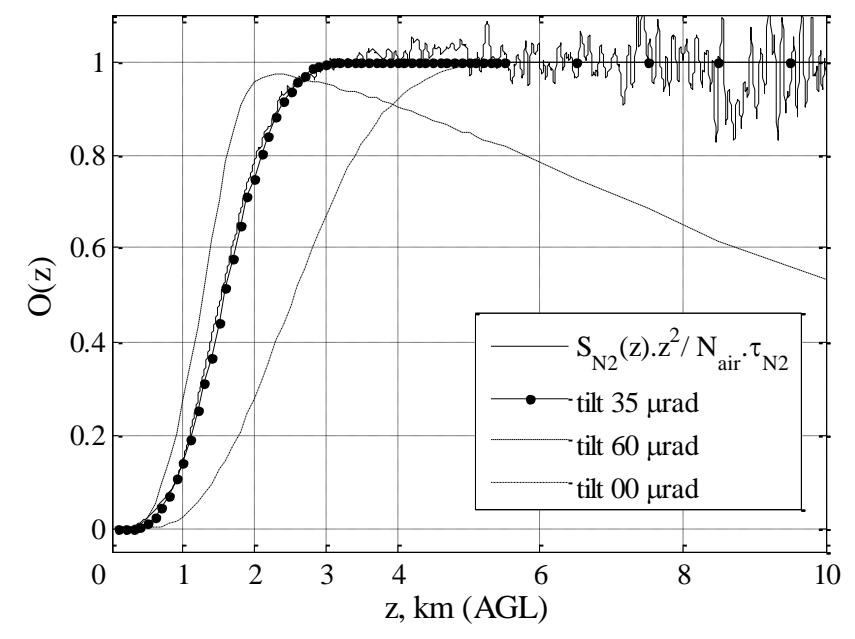

Fig. 4. Calculated overlap functions for different mirror tilt angles, compared to derived from acquired nitrogen signal overlap function. The overlap functions were calculated for the telescopes focused at $10 \mathrm{~km}(0.1 \mathrm{~mm}$ fiber shift away from the mirrors), whereas the overlap estimate uses nitrogen signal recorded on 9 July 2008, averaged for $1 \mathrm{~min}$ (1800 laser shots) and over $37.5 \mathrm{~m}$ (10 bins).

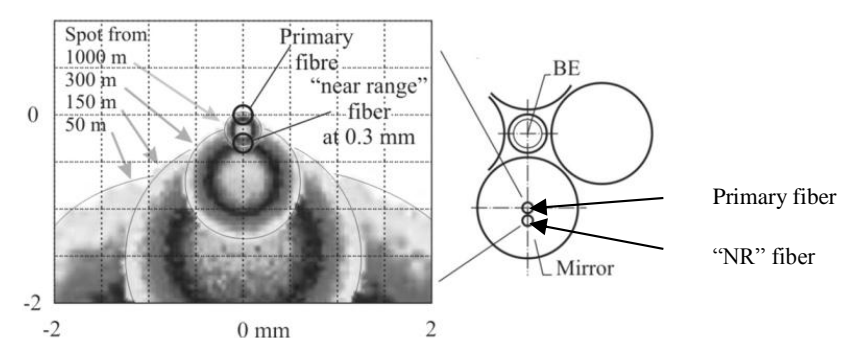

Fig. 5. Positions of the primary and NR fibers and the blur spot contours at the focal plane of a telescope mirror: left - modeled blur spot contours from different distances; right - a sketch of the receiver showing the positions of the primary and NR fibers, the beam expander $(\mathrm{BE})$, and the telescope mirrors.

the expander at $35 \mu \mathrm{rad}$, which results in full overlap at approximately $3 \mathrm{~km}$. Modeled overlap functions of a single mirror for several tilt angles are presented in Fig. 4. The overlap functions were calculated by ray-tracing $\left(\mathrm{OSLO}^{\circledR}\right)$ assuming flat-top energy distribution of the laser beam. An overlap function, derived from a nitrogen Raman signal measured by the system at mirror tilt angle of $35 \mu \mathrm{rad}$, is presented for comparison. A tilt with more than $45 \mu \mathrm{rad}$ results in slight loss of full overlap at about $10 \mathrm{~km}$, whereas the lidar does not reach full overlap at any distance for tilt angles $\geq 60 \mu \mathrm{rad}$.

As seen from Fig. 4, the increase of the tilting angle above $35 \mu \mathrm{rad}$ does not lead to significant lowering of the full overlap region and the overlap value is close to zero for altitudes below $500 \mathrm{~m}$. To extend the operational distance of the lidar down to $150 \mathrm{~m}$, we use signals from the incomplete overlap region; the signal level below $1 \mathrm{~km}$ is enhanced by using an additional fiber, as will be described in the following section.
Deriving water vapor mixing ratio using the incomplete overlap region is possible since the Raman backscatter is excited by a single monochromatic beam and the reflective type lidar telescopes used in our design. Hence, the ratio of overlap functions (Eq. 7) at the telescope output (respectively fiber input) is range-independent for any altitude. Possible deviation from the range independence could stem from the chromatic aberrations introduced by the telescope protective windows and from the edge filters, installed before the fibers. The ray tracing estimation shows that the $20 \mathrm{~mm}$ thick, fusedsilica windows, installed at $15^{\circ}$ to the mirrors optical axes, introduce negligible lateral color (less than $0.1 \mu \mathrm{m}$ ) for water vapor and nitrogen wavelengths and practically do not influence the range independence of the overlap ratio. The ratio is practically range-independent, even for observations taken from tens of meters, when the chromatic focal shift due to the divergence of the incident on the windows radiation increases. The edge filters are deposited on $3 \mathrm{~mm}$ thick, fused silica substrates and installed in front of the fibers in a convergent beam (f/3.33 telescopes). Ray-tracing indicates $5 \mu \mathrm{m}$ chromatic focal shift, which has negligible influence on the ratio of ray-traced overlaps at the considered wavelengths. In conclusion, there are no important chromatic aberrations for the current telescope receiver design and the overlap ratio can be considered range-independent. The range independence of the other terms of Eq. (7), which includes the parameters of the spectral separation and detection unit, will be evaluated in the corresponding sections.

\subsubsection{Extension of near range coverage}

As seen from Fig. 4, the value of the overlap function is close to zero at altitudes below $500 \mathrm{~m}$ because of the narrow FOV and the non-coaxial configuration of the lidar. As a result, the near-range signal-to-noise ratio is low and does not allow daytime water vapor retrieval with statistical error lower than $10 \%$ below $225 \mathrm{~m}$. Two methods are usually used to extend the operational distance to lower altitudes: an additional receiver, including an additional telescope and a polychromator (Engelbart et al., 2006; Reichardt et al., 2012); or a dual field-of-view telescope with an additional polychromator (Goldsmith et al., 1998). Since both methods increase the complexity of the lidar, reduce its reliability and complicate the data processing, we developed a new approach to extend the near range coverage. In this approach, improvement of the near range collection efficiency is achieved by using an additional "near range" (NR) fiber in one of the telescopes. The NR fiber is laterally displaced from the primary fiber in direction opposite to the beam expander at a position where the blurred image of the laser beam, coming from distances close to the lidar, is formed as shown in Fig. 5.

Simulated lidar signals in terms of the effective receiver aperture divided by the squared range $\mathrm{AO}(z) / z^{2}$ are shown in Fig. 6 . The overlap functions are calculated by ray-tracing for mirror tilt of $35 \mu \mathrm{rad}$, and fiber positions of $0.1 \mathrm{~mm}$ behind 


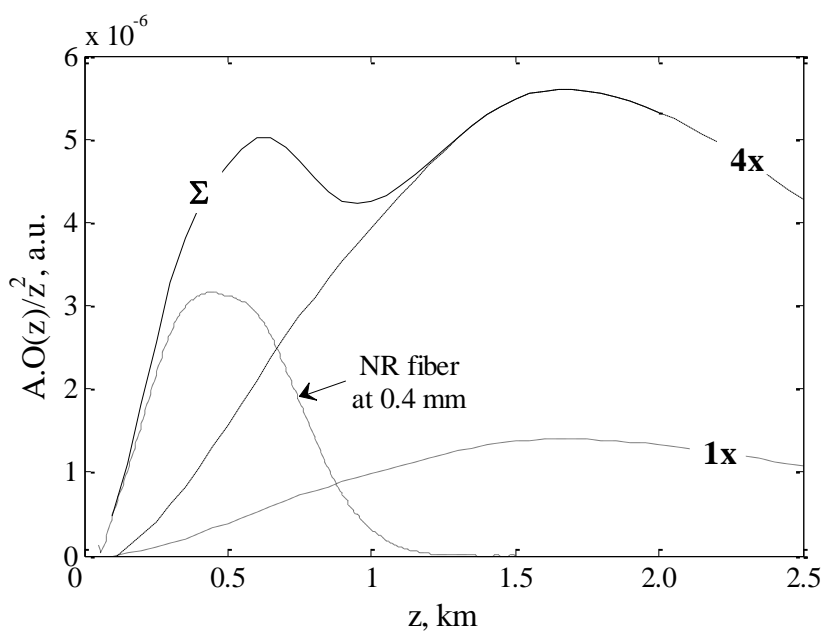

Fig. 6. Simulated signals in terms of $\mathrm{AO}(z) / z^{2}$ disregarding the atmospheric transmission: signal from one telescope $(1 \times)$, signal from four telescopes $(4 \times)$, total signal from four telescopes including the contribution of the near range fiber $(\Sigma)$.

the focal plane (focusing at $10 \mathrm{~km}$ ). Due to the fiber displacement, the NR fiber signal is higher than the principal fiber signal within the range $50-800 \mathrm{~m}$ in cases of one telescope. The signals from the four telescopes, together with the additional NR signal, are optically summed on the respective photomultiplier cathode. The resulting "sum" signals with and without NR fiber (see Fig. 6) clearly show the contribution of the NR fiber below $1 \mathrm{~km}$.

The use of a NR fiber enhances the near range signal level, but simultaneously increases daylight background, thus reducing the daytime SNR of the far range. To evaluate the influence of the NR fiber on near and far range measurements, we calculated the daytime detection limit of the lidar. The detection limit is defined as the mixing ratio measured with relative error of $10 \%$ (or SNR $=10$ ). Only the water vapor signal is considered in the analysis, since the detection limit is defined mostly by its SNR. The signal variance is estimated using Poisson statistics, and the relative mixing ratio error is

$\frac{\delta q}{q}(z) \approx \frac{\sigma_{P_{\mathrm{H}_{2} \mathrm{O}}}}{P_{\mathrm{H}_{2} \mathrm{O}}}(z)=\frac{\sqrt{P_{\mathrm{H}_{2} \mathrm{O}}(z)+B_{\mathrm{H}_{2} \mathrm{O}}}}{P_{\mathrm{H}_{2} \mathrm{O}}(z)} \frac{1}{\sqrt{n}}$,

where $P_{\mathrm{H}_{2} \mathrm{O}}(z)$ is the background corrected water vapor Raman lidar signal, $B_{\mathrm{H}_{2} \mathrm{O}}$ is the light background, both in terms of count rate, and $n$ is the product of the number of averaged spatial bins and the number of laser shots. The daylight background is taken as $65 \mathrm{MHz}$, a value typical for the water vapor signal acquired with the lidar around 2008 summer solstice. This background corresponds to sky zenith radiance of approximately $15 \mathrm{mWcm}^{-2} \mathrm{sr}^{-1} \mu \mathrm{m}^{-1}$ at the water vapor wavelength, assuming total channel efficiency of $6.8 \%$ and bandwidth of $0.3 \mathrm{~nm}$. The Raman signal is calculated using ray-traced overlaps, molecular two-way transmission from US standard atmosphere, aerosol profile with a constant ex-

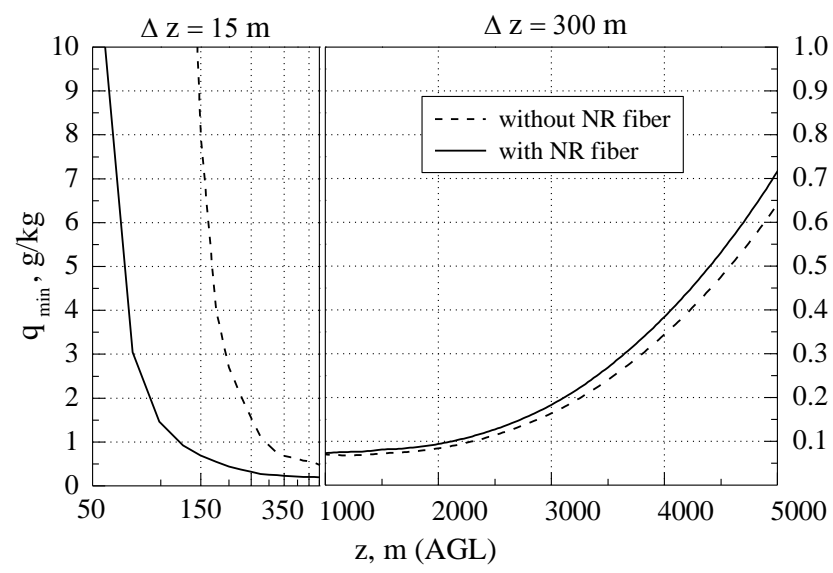

Fig. 7. NR fiber influence on the minimum detectable water vapor mixing ratio profiles $(\mathrm{SNR}=10$ ): averaging $30 \mathrm{~min}, 65 \mathrm{MHz}$ sky background in the water vapor channel, molecular two-way attenuation from US standard atmosphere, aerosol two-way transmission assuming constant aerosol extinction at $550 \mathrm{~nm}$ of 0.11 up to 1.5 $\mathrm{km}$ with Angström coefficient of 1.4.

tinction up to $1 \mathrm{~km}$ of $0.16 \mathrm{~km}^{-1}$ at $550 \mathrm{~nm}$, and Angström turbidity coefficient of 1.4 .

The modeled daytime detection limits, with and without NR fiber, are compared in Fig. 7 for time averaging of $30 \mathrm{~min}$ and spatial averaging of $15 \mathrm{~m}$ below, and $300 \mathrm{~m}$ above, $1 \mathrm{~km}$. The detection limit without the NR fiber is $8.5 \mathrm{~g} \mathrm{~kg}^{-1}$ at $150 \mathrm{~m}$ and increases to more than $10 \mathrm{~g} \mathrm{~kg}^{-1}$ for lower altitudes, a value insufficient for valuable measurements within the first $150 \mathrm{~m}$. The use of a NR fiber reduces the detection limit to less than $1 \mathrm{~g} \mathrm{~kg}^{-1}$ at $150 \mathrm{~m}, 3 \mathrm{~g} \mathrm{~kg}^{-1}$ at $75 \mathrm{~m}$ and to values above $10 \mathrm{~g} \mathrm{~kg}^{-1}$ below $50 \mathrm{~m}$. The right plot of Fig. 7 presents the corresponding detection limit profiles for altitudes above $1 \mathrm{~km}$. The detection limit at $5 \mathrm{~km}$ without the NR fiber is $0.65 \mathrm{~g} \mathrm{~kg}^{-1}$ and increases slightly to about $0.71 \mathrm{~g} \mathrm{~kg}^{-1}$ with the fiber. Space averaging of $600 \mathrm{~m}$ reduces these values to $0.42 \mathrm{~g} \mathrm{~kg}^{-1}$ without and to $0.46 \mathrm{~g} \mathrm{~kg}^{-1}$ with the NR fiber. The decrease in detection limit could be compensated by increasing the laser output power with approx. $10 \%$, if necessary.

\subsubsection{Spectral unit}

To achieve long-term data consistency, system stability and negligible range dependence of the calibration constant, the Raman signals are spectrally isolated by a fiber-coupled grating polychromator. The use of a grating-based, instead of a filter-based, polychromator eliminates the long-term gradual shift of the central wavelength and any changes in the transmission, related to the interference-filter-based devices. Furthermore, grating polychromators, contrary to interferencefilter-based polychromators, allow easy selection of the central wavelength position and bandwidth, hence optimization of the efficiency and minimization of the systematic errors 


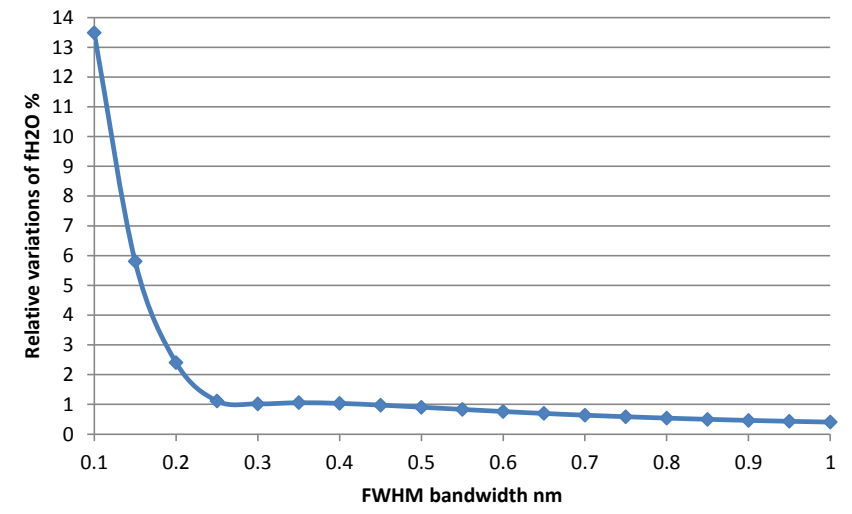

Fig. 8. Minimum values of the relative variations of $f_{\mathrm{H}_{2} \mathrm{O}}=$ $\int \sigma_{\mathrm{H}_{2} \mathrm{O}}^{\pi}(\lambda, T) I_{x \mathrm{H}_{2} \mathrm{O}}(\lambda) \mathrm{d} \lambda$ as a function of the water vapor channel FWHM bandwidth for the temperature range $-60^{\circ} \mathrm{C}+40^{\circ} \mathrm{C}$.

related to the temperature dependence of the Raman cross sections.

The polychromator is designed for narrow band isolation of the Q-branches of ro-vibrational water vapor and nitrogen Raman spectra with high-throughput. An additional oxygen channel for determining the aerosol extinction correction of the water vapor concentration (Dinoev et al., 2006) was built, but is still not in use. Introducing of a third signal (oxygen) allows more precise correction for aerosol differential extinction but also introduces additional noise. Therefore, its use is justified only in a case of serious aerosol perturbation. More detailed investigation on the use of this correction is planned in near future.

Special attention was paid to reduce the temperature dependence of $C_{\mathrm{L}}$ by selecting the bandwidth and the central wavelength of the water vapor channel, thus minimizing $f_{\mathrm{H}_{2} \mathrm{O}}$ (Eq. 8). Figure 8 shows the minimal variations of $f_{\mathrm{H}_{2} \mathrm{O}}$ in percent, with respect to its value at $0{ }^{\circ} \mathrm{C}$, for the temperature range $-60^{\circ} \mathrm{C}+40^{\circ} \mathrm{C}$ as a function of the water channel FWHM bandwidth. The $f_{\mathrm{H}_{2} \mathrm{O}}$ functions are calculated using spectral data from Avila et al. (1999) and a Gaussian instrumental function. The minimum values of $f_{\mathrm{H}_{2} \mathrm{O}}$ for each bandwidth are obtained by varying the central wavelength.

As seen from Fig. 8, the $f_{\mathrm{H}_{2} \mathrm{O}}$ variations are $1 \%$ or less for bandwidths larger than $0.25 \mathrm{~nm}$. The optimal central wavelength for these bandwidths is around $407.45 \mathrm{~nm}$ and varies slightly with the bandwidth. We have chosen the bandwidth of $0.33 \mathrm{~nm}$ centered at $407.45 \mathrm{~nm}$, which is a compromise between the signal and the daylight noise levels. The nitrogen and oxygen slits are centered at 386.7 and $375.4 \mathrm{~nm}$, respectively. The relative change of the transmitted intensity in the nitrogen channel is $0.4 \%$ per $100 \mathrm{~K}$ (Whiteman, 2003), which can be considered negligible.

The polychromator optical layout is presented in Fig. 9. The optical fibers, delivering the light from the telescopes, are arranged vertically and act as a polychromator entrance slit. The effective slit width and height are defined by the

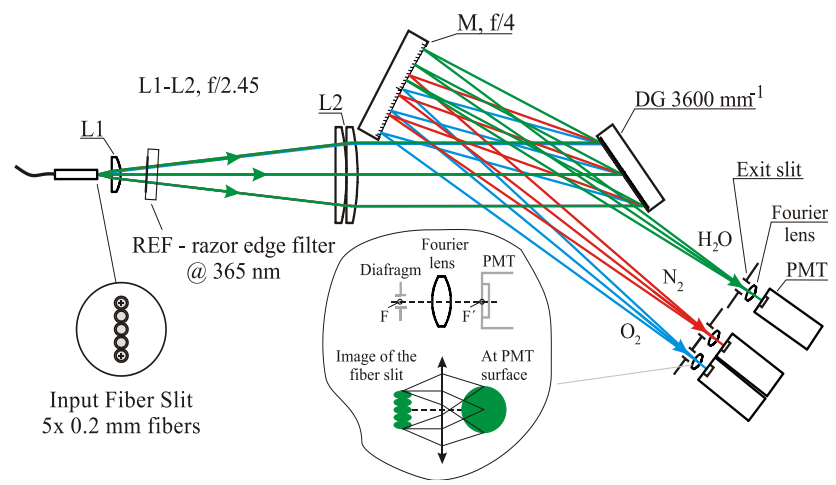

Fig. 9. Optical layout of the polychromator: L1-L2 - spherical lens collimator (f/2.39, F = $165 \mathrm{~mm}), \mathrm{REF}-$ Raman edge filter, DG holographic diffraction grating $\left(3600 \mathrm{~mm}^{-1}, 85 \times 85 \mathrm{~mm}^{2}\right), \mathrm{M}-$ parabolic mirror (f/4, F = $445 \mathrm{~mm})$, PMT - photomultiplier tubes.

fiber core and external diameter and are, respectively, 0.2 and $1.1 \mathrm{~mm}$. The three-lens collimator (L1-L2) with effective focal length of $165 \mathrm{~mm}(\mathrm{f} / 2.39)$ is designed with standard plano-convex spherical lenses. The pre-collimating lens L1 matches the f-numbers of the fiber and the spherical doublet $\mathrm{L} 2$. The position of $\mathrm{L} 1$ is optimized with the OSLO ${ }^{\circledR}$ ray-tracing program for minimum aberrations. The collimated beam is projected onto a $3600 \mathrm{~mm}^{-1}$ blazed holographic grating (Carl Zeiss AG) installed at incidence angle of $35.7^{\circ}$ (diffraction angle $62^{\circ}$ at water vapor wavelength). A parabolic mirror $\mathrm{M}$ focuses the diffracted beams on the respective exit slits. To reduce the aberrations in the water channel, the mirror is in a close to on-axis configuration for the water vapor wavelength. All slits are $1 \mathrm{~mm}$ wide, $8 \mathrm{~mm}$ in height and match the images of the entrance slit. The image width at the water vapor wavelength was found to be $0.93 \mathrm{~mm}$ only if the optical magnification of 2.7 (collimator and mirror) and the angular grating magnification of 1.73 are taken into account, and increases to approximately $1 \mathrm{~mm}$ if the aberrations are considered. The bandwidth of the spectral transmission function was found to be around $0.33 \mathrm{~nm}$ if calculated using the reverse linear dispersion of the polychromator (about $0.3 \mathrm{~nm} \mathrm{~mm}^{-1}$ at the water vapor wavelength). The more precise ray-tracing calculation $\left(\mathrm{OLSO}^{\circledR}\right)$, which takes into account the system aberrations, confirmed this value. The calculated spectral transmission function for water vapor is presented in Fig. 10 as an example.

The total efficiency of the lidar receiver is defined generally by the polychromator transmittance and the PMT efficiency. To reduce the polychromator losses we use AR coated lenses and a dielectric mirror coating. The polychromator transmission, however, is defined mostly by the grating efficiency. We measured $36 \%$ absolute grating efficiency (deviation angle of $26.3^{\circ}$ ) at the water vapor wavelength, a slightly reduced value compared to the $38 \%$ efficiency specified by the producer for an auto-collimation configuration. The total polychromator transmittance at the water vapor wavelength 


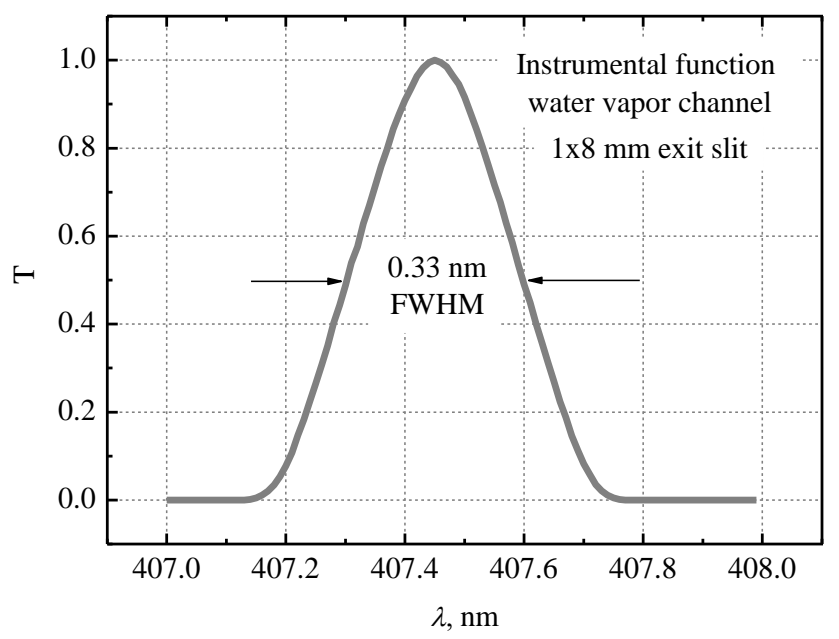

Fig. 10. Instrumental function of the water vapor channel calculated with $\mathrm{OLSO}^{\circledR}$ for exit slit width of $1 \mathrm{~mm}$. The function maximum is centered at $407.45 \mathrm{~nm}$ for minimal temperature influence.

becomes $33 \%$ when the losses due to the coatings and the internal transmittance of the collimator optics are taken into account.

The polychromator rejection of the elastic stray light in the water vapor channel was measured by a stack of calibrated neutral density filters and was found to be $7 \times 10^{5}$. The elastic stray-light suppression of the channel is further enhanced by Semrock ${ }^{\circledR}$ Rasor edge filters installed in front of each fiber (in the telescope assembly) and at the polychromator entrance. Since the filters rejection at $355 \mathrm{~nm}$ is $10^{6}$, the total rejection of elastic light in the water channel is estimated to be $10^{17}$. The cross talk between the nitrogen and water vapor channels was measured using calibrated neutral density filters and the first nitrogen Stokes, produced by stimulated Raman scattering. The value of the cross talk was found to be $0.5 \times 10^{-5}$, low enough to be neglected as a cause of systematic errors even in the high troposphere.

As described in Sect. 2.1, the optics between the telescope and the photomultipliers can cause range dependence. To eliminate or reduce this range dependence to negligible levels, we use a grating polychromator, fiber-coupled to the telescope assembly. Fiber coupling is essential for the elimination of $C_{\mathrm{L}}$ range dependence since fibers perform aperture scrambling and fix the object position and size at the polychromator entrance, making it independent of the position and size of the image of the laser beam at the telescopes output. Furthermore, fiber coupling not only simplifies the lidar design and alignment, but also improves the system alignment stability compared to a free-space connection. Since the optical fibers do not perform complete angular scrambling, the angle of the light cone at the fibers exit depends on the observation range. This dependence is noticeable at distances shorter than $1 \mathrm{~km}$ and, combined with the polychromator aberrations, could lead to a range-dependent error. To estimate the magnitude of this error, we used a ray-tracing model of the polychromator. The simulation showed maximum relative errors in the water vapor mixing ratio between -0.4 and $+0.1 \%$ for the distance range $50-600 \mathrm{~m}$. To avoid errors due to vignetting of the optical beams inside the polychromator, all the optical elements, including the grating, are oversized. To cancel the known effect of the PMT high spatial non-uniformity, we use field lenses (Fabry, 1921) at the output of the polychromator, which convert the image of the input fiber slit (formed by five fibers) to single spots on the PMTs surfaces.

\subsubsection{Light detection and signal acquisition}

Hamamtsu metal channel dynode photomultipliers (PMT) are used for detecting the light in the Raman channels. This type of photomultipliers has been chosen because this type shows good counting characteristics and can be operated in both analog and photon-counting mode. Furthermore, this small size type allows installation at the polychromator output without additional steering optics. To enhance the detection efficiency of the water vapor channel, we use high quantum efficiency (QE) photomultipliers (R7600U-200). The photocathode of this PMT type is ultra-bialkali with $40 \%$ quantum efficiency at $400 \mathrm{~nm}$. The nitrogen and the oxygen channels are equipped with Hamamatsu photodetector modules type $\mathrm{H} 6780$ with maximum quantum efficiency of $20 \%$ at $400 \mathrm{~nm}$. In order to preserve the photodetector modules from the high amplitude of the signals, and to use photoncounting mode, OD 1 and OD 0.6 neutral density (ND) filters are installed in the nitrogen and the oxygen channels, respectively.

During the four years of operation of the lidar we noticed a slight, steady decrease in the measured water vapor mixing ratio compared to the regular radiosonding. The decrease is more pronounced during the summer months, as shown in detail in the companion paper (Brocard et al., 2013), and requires periodic lidar recalibration. Analyzing the possible reasons for this decrease, we concluded that reduction of the photocathode sensitivity due to aging of the water vapor PMT is the most probable cause. A possible reason for faster aging of the water PMT is the higher intensity of the solar background received by this PMT, compared to the background received by the nitrogen PMT. The reason for this difference is the OD 1 ND filter used installed in front of the nitrogen PMT. Another possible reason could be the aging rate difference but since the ultra-bialkali photocathodes are relatively new, there is no information about their aging. To monitor the absolute change in sensitivity of the water vapor PMT and its relative change versus the nitrogen PMT, we are developing a LED-based monitoring system. The system will operate during standby periods of the lidar (rain, low clouds) and the information will be used for automatic correction of the lidar calibration constant and as an indication for PMT exchange. 
Data acquisition is carried out by a Licel GmbH transient recorder having simultaneously operated $250 \mathrm{MHz}$ counter and a 12 bit, 40 MSPS analog digitizer. The minimum time resolution is $25 \mathrm{~ns}$ corresponding to a $3.75 \mathrm{~m}$ spatial resolution. The transient recorder channels are synchronously triggered by an optical trigger activated by the $532 \mathrm{~nm}$ laser radiation. Optical triggering eliminates the electric connection between the laser and the transient recorder, thus reducing any possible electromagnetic interference. The raw signals are acquired in analog-to-digital (AD) and photon-counting $(\mathrm{PhC})$ modes with spatial resolution of $3.75 \mathrm{~m}$ and averaging over 1800 laser shots (approximately one minute).

\subsubsection{Lidar automation}

The lidar autonomous operation is ensured by two computers. The first one, a lidar automat computer (LAC), controls the lidar hardware, records the hardware operational parameters and acquires the raw lidar data. A second, data treatment computer (DTC), is designated for automated onsite data treatment and data transfer.

A lidar automat (LA) code that runs in LabView environment on LAC controls the lidar and can be operated in autoor manual modes. In the auto mode, the lidar operates autonomously after initial activation by the operator. In this mode LAC controls the lidar hardware and terminates and resumes the measurements, depending on the weather conditions. Weather information is supplied by a precipitation detector and a collocated ceilometer. The program stops the lidar in case of precipitation, clouds lower than $500 \mathrm{~m}$, or dense fog and restarts it when the cloud base is higher than $1.5 \mathrm{~km}$ and if no rain or fog are detected within a predefined time. After initial timeout for the laser heat-up, the acquisition system is activated and the lidar is operational. The laser power is continuously monitored and an automated alignment of the harmonic crystals is activated when the power at $355 \mathrm{~nm}$ drops below a predefined level. All metadata relevant to the lidar, including the laser power, are logged. In manual mode, the automated procedures for lidar start-up, operation, and shutdown are deactivated, leaving the control to the operator.

The real-time data treatment is performed by an automated data treatment (ADT) program, developed under Matlab and run on DTC. Each half-hour the program reads the available raw data files, processes the data, and stores the result in a file available for upload. The file consists of a water vapor mixing ratio profile with the corresponding statistical error. Remote control of the system is available via secured Internet connection.

\section{Data processing}

\subsection{Profile retrieval}

The data treatment software was designed to autonomously process the raw data in near real-time and to transfer the water vapor mixing ratio profile and its random error estimate to the MeteoSwiss data base. The data treatment procedure is carried out every half-hour when data are available and consists of the following steps: desaturation of the PhC signals and scaling the $\mathrm{AD}$ water vapor signal to $\mathrm{PhC}$, calculation of the signal variance from Poisson statistics, background subtraction, time and space averaging, water vapor mixing ratio calculation using predefined calibration constant, and Rayleigh correction. The PhC signals from all detection channels are desaturated using the assumption for "non-paralyzable" counter (Ingle and Crouch, 1972):

$P_{i}^{\mathrm{d}}=\frac{P_{i}}{\left(1-\vartheta P_{i}\right)}$

where $P_{i}^{\mathrm{d}}$ is the desaturated count rate from a distance bin $i$, $P_{i}$ is the measured count rate and $\vartheta$ is the counter dead time. Since some of the daytime water signals are oversaturated, we use glued water signals consisting of $\mathrm{PhC}$ and scaled $\mathrm{AD}$ signals for the processing. The AD signal is scaled to match the $\mathrm{PhC}$ signal according to the following formula:

$P_{i}^{\mathrm{AS}}=\frac{A_{i}-u_{0}}{C}$

where $P_{i}^{\mathrm{AS}}$ is scaled analog signal $A_{i}, C$ is scaling coefficient and $u_{0}$ is the electric offset of the channel ADC. The dead time and the scaling coefficient are calculated by a linear regression of $\mathrm{PhC}$ to $\mathrm{AD}$ signals and the electric offset is derived from the last 1000 bins of nighttime-acquired AD signals. The glued signal is equal to $P_{i}^{\mathrm{AS}}$ for photon count rates above a predefined threshold, and equal to $P_{i}^{\mathrm{d}}$ for photon count rates below this threshold. The signal noise is calculated before the background subtraction, using either a signal variance from Poisson statistics or a variance estimate from a digitized analog signal (Liu et al., 2006). The background value in each channel is determined from the last 1000 time bins. The corrected signals are averaged over $30 \mathrm{~min}$. The spatial averaging is done using a window size, which is variable as a function of height. The window size is defined by the software to maintain the relative error below $10 \%$. The relative error is calculated using Eq. (12). The water vapor mixing ratio is derived from the ratio of water vapor to nitrogen Raman signals following Eq. (5), where the calibration constant is obtained from a set of intercomparisons with radiosondes. Finally, the water vapor profile is corrected for molecular atmospheric differential transmission using US standard atmosphere model. 


\subsection{Error budget}

The measurement error of the water vapor profile has three main components (Whiteman et al., 2001): (1) uncertainty of the calibration constant, (2) uncertainty in the differential atmospheric extinction, and (3) uncertainty of the water vapor to nitrogen signal ratio.

The uncertainty of the calibration constant is mostly systematic and is due to (1) uncertainty of the reference instrument, (2) uncertainty due to the calibration methodology, and (3) systematic errors due to the lidar design. The first two error sources are widely discussed in the literature (e.g. Nash et al., 2011; Ferrare et al., 1995; Turner et al., 2000, 2002; Evans et al., 2000; Leblanc et al., 2012) and, as shown in (Turner et al., 2002), the existing reference instruments and calibration methods allow for achieving uncertainty on the order of $5 \%$. The systematic errors caused by the instrument design are much less discussed and usually correction functions are applied to reduce their magnitude (e.g. Whiteman et al., 2012; Whiteman, 2003; Turner et al., 2002). In this work we have tried to identify, analyze and finally reduce the instrumental systematic errors through the lidar design. The system error sources were discussed in the Part 2 companion paper (Brocard et al., 2013) where the technical solutions used to reduce the systematic errors were already presented together with the description of the respective subsystems of the lidar. Here we will present a brief summary of these errors. The systematic errors in the overlap region (near to midrange) caused by the optical imperfection of the receiver have been reduced to less than $1 \%$ by using a grating polychromator fiber, coupled to a reflective telescope. The systematic errors induced by PMT non-uniformity were reduced to a negligible level by the field lenses installed in front of each PMT. By reducing the error magnitude in the overlap region, we eliminated the need for overlap corrections and related errors. The systematic error caused by the temperature sensitivity of the water vapor Raman cross section was reduced to around $1 \%$ by proper selection of water vapor central wavelength and bandwidth.

The uncertainty of the differential atmospheric transmission arises mostly through aerosol scattering, but is relatively low in conditions of normal visibility. Therefore, aerosol correction is not applied in the current version of the lidar.

The uncertainty of the water vapor to nitrogen signal ratio has a systematic and a random component. The additive systematic errors are caused by fluorescence, elastic signal penetration in the water channel, and Raman channels cross talk. The error due to fluorescence and elastic signal penetration in our system is reduced to negligible levels by blocking the elastic light at the telescope output and at the polychromator input. The measured cross talk level between water vapor and nitrogen Raman signals is low enough for tropospheric measurements but may cause wet bias in the tropopause and the low stratosphere regions. The cross talk level can be easily further reduced by a band-pass filter but since the lidar is

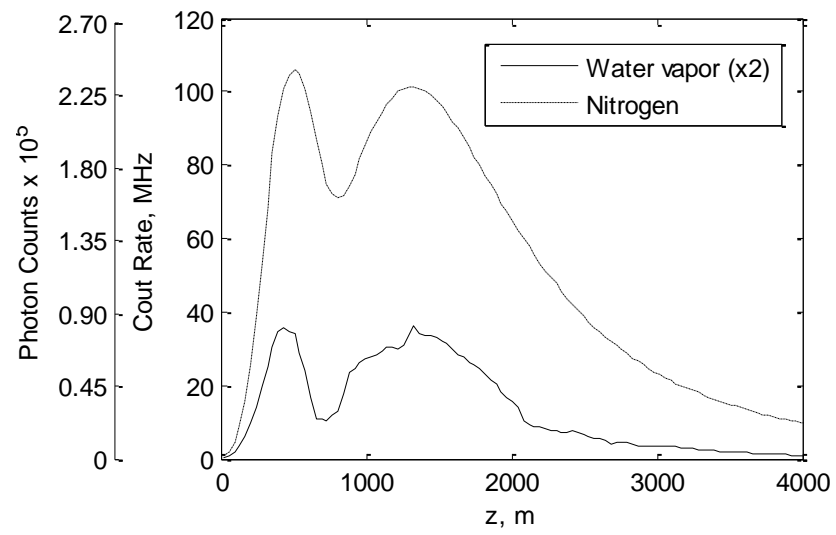

Fig. 11. Lidar signals from water vapor and nitrogen channels.

designed and used for tropospheric measurements, this is not done. Other systematic error sources are due to PMT saturation in photon-counting mode. The magnitude of these errors is reduced to levels lower than the random error by desaturation and constraining the desaturated signal to simultaneously recorded analog signals.

The random component due to photon detection noise is the dominating and highly variable error source in water vapor measurement. Therefore it is calculated for each lidar profile. The relative error $\frac{\partial q(z)}{q(z)}$ of the water vapor measurement is estimated from the standard errors of the Raman signals $\sigma_{x}(z)$ and their respective daytime background $\sigma_{\mathrm{B} x}(z)$ following error propagation formulas:

$$
\frac{\partial q(z)}{q(z)}=\sqrt{\frac{\sigma_{\mathrm{H}_{2} \mathrm{O}}^{2}(z)+\sigma_{\mathrm{B}_{\mathrm{H}_{2} \mathrm{O}}}^{2}}{\left[P_{\mathrm{H}_{2} \mathrm{O}}(z)-P_{\mathrm{B}_{\mathrm{H}_{2} \mathrm{O}}}\right]^{2}}}+\frac{\sigma_{\mathrm{N}_{2}}^{2}(z)+\sigma_{\mathrm{B}_{\mathrm{N}_{2}}}^{2}}{\left[P_{\mathrm{N}_{2}}(z)-P_{\mathrm{B}_{\mathrm{N}_{2}}}\right]^{2}}
$$

where $P_{x}$ is the number of the signal counts summed over the averaging time and space range, and $P_{\mathrm{B} x}$ is the number of the respective background counts. The statistics of the signals detected in photon-counting mode are governed by the Poisson distribution, i.e. the standard error is equal to the square root of the number of photons counted.

The absolute error of the lidar water vapor profile was estimated by comparison of one year humidity measurements simultaneously obtained by the lidar, collocated regular radiosonding, a microwave radiometer, and a GPS receiver. The results of this intercomparison are discussed in the companion paper (Brocard et al., 2013) and show good agreement of the three measurement techniques. This agreement signifies that the absolute error of the lidar profiles is at least within the uncertainty of the mentioned conventional techniques. 

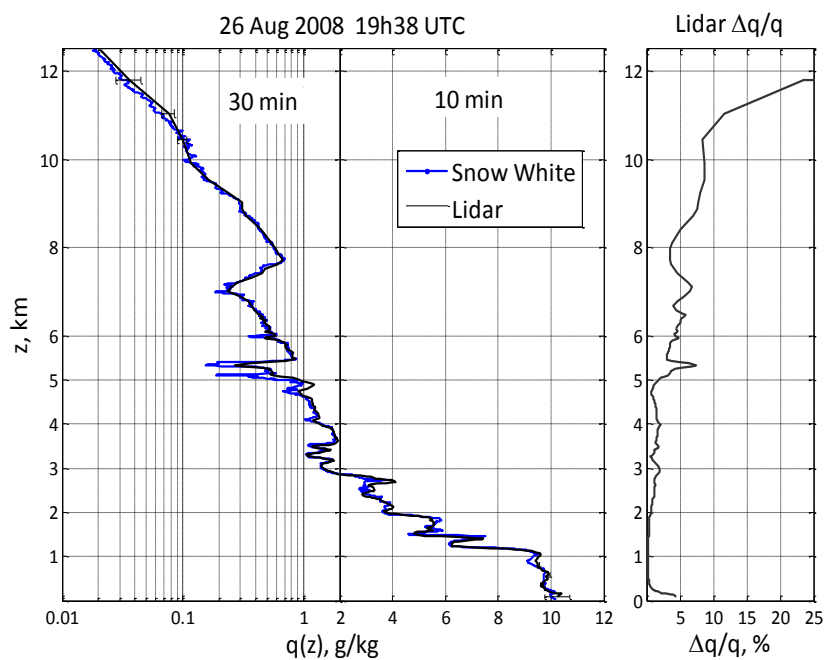

Fig. 12. Left: Vertical water vapor mixing ratio profiles measured quasi-simultaneously by the lidar and an equipped-with Snow White radiosonde (chilled mirror hygrometer). The sonde was launched at 19:38 UTC. Time averaging $10 \mathrm{~min}$ below $3 \mathrm{~km}$ and 30 min above. The vertical resolution is variable; initial $15 \mathrm{~m}$, above $4 \mathrm{~km}$ - minimum $30 \mathrm{~m}$, above $6.5 \mathrm{~km}$ - minimum $105 \mathrm{~m}$, above $9 \mathrm{~km}$ - minimum $300 \mathrm{~m}$; above $11 \mathrm{~km}$ the resolution is $900 \mathrm{~m}$ (maximum allowed). Right: Lidar statistical error profile.

\section{Measurement examples}

Figure 11 shows nighttime recorded nitrogen and water vapor desaturated photon-counting signals, summed over $5 \mathrm{~min}$ $\left(9 \times 10^{3}\right.$ laser shots) using $37.5 \mathrm{~m}$ (10 bin) vertical resolution, presented in a count rate $(\mathrm{MHz})$ and photon counts. The desaturated nitrogen signal has a maximum value of $110 \mathrm{MHz}$, whereas the water vapor signal, recorded in relatively dry nighttime conditions, reaches $17 \mathrm{MHz}$. The first peak in Raman signals at approximately $0.7 \mathrm{~km}$ clearly shows an increase in the collection efficiency due to the NR fiber. The second peak, at approximately $1.3 \mathrm{~km}$, is due to signal collection by the primary fibers in the four telescopes.

The lidar calibration constant is derived using vertical profiles taken by either Vaisala RS92 or Snow White (Vömel et al., 2003) radiosondes. The calibration flights were carried out in nighttime and stable weather conditions. The Snow White dew point profile is converted to mixing ratio with Goff-Gratch equations for saturation pressure over water and ice (1946 formulation), accounting for the internal flag indicating ice formation on the mirror. The same calibration constant is used for several months and is periodically verified. Recalibration is done when the calibration error exceeds a predefined level. The calibration constant used in the following examples was derived from a Vaisala RS92 profile using the first $6 \mathrm{~km}$ of the profile.

Figure 12 shows comparison of nighttime water vapor mixing profiles obtained by the lidar and an equipped-with Snow White radiosonde, launched from the lidar site on
26 August 2008 at 19:38 UTC. The left plot presents comparison of the mixing ratio profiles, and the right plot shows the statistical error profile of the lidar measurement. Mixing ratios higher than $2 \mathrm{~g} \mathrm{~kg}^{-1}$ are presented in a linear scale, whereas the smaller values are plotted in a logarithmic scale. The linear scale compares the data up to approximately $3 \mathrm{~km}$, an altitude reached by the radiosonde for about $10 \mathrm{~min}$, assuming radiosonde ascending rate of about $5 \mathrm{~m} \mathrm{~s}^{-1}$. For better comparison with the sonde profile, the lidar data were averaged for $10 \mathrm{~min}$ within the first $3 \mathrm{~km}$. The logarithmic scale compares the lidar and the radiosonde using a lidar mixing ratio profile obtained with $30 \mathrm{~min}$ time average. The vertical resolution of the lidar is variable in order to keep the statistical error below $10 \%$. The initial resolution is $15 \mathrm{~m}$, it is reduced to $30 \mathrm{~m}$ above $4 \mathrm{~km}$, to $105 \mathrm{~m}$ above $6.5 \mathrm{~km}$, and to $300 \mathrm{~m}$ above $9 \mathrm{~km}$. Above $11 \mathrm{~km}$ the range resolution is $900 \mathrm{~m}$. Error bars at the beginning and the end of the lidar profile present the random error of the lidar measurement, estimated from the lidar signals.

The mixing ratio profiles match exceptionally well within the whole range from $75 \mathrm{~m}$ up to $12.5 \mathrm{~km}$. The very good agreement in the lower parts of the profiles, retrieved from the incomplete overlap region, demonstrate the negligible range dependence of the lidar calibration constant. The small discrepancies between the sonde and the lidar, seen in the lower part of the profile, can be explained by the different temporal and spatial resolutions of the two instruments, amplified by the high temporal and spatial variability of water vapor. The validity of the last argument is supported by the high temporal variability of the water vapor field clearly seen in the $10 \mathrm{~min}$ resolution time series presented in Fig. 14. The lidar correctly reproduces the atmospheric stratification. The differences between the sonde and the lidar in the $5-5.5 \mathrm{~km}$ region are probably caused by the difference in the air masses sampled by the two instruments, or by the smoothing effect of the longer time averaging by the lidar, or both.

The two profiles compare very well in the region 6.5$11 \mathrm{~km}$, despite the reduced to $105 \mathrm{~m}$ lidar resolution. The very good correlation in this region is an indicator for the negligible temperature sensitivity of the measurements, i.e. the correct selection of polychromator central wavelengths and bandwidths. Above 11 the relative error increases above $10 \%$ and to compensate, the software increases the vertical averaging to $900 \mathrm{~m}$, defining a measurement point at $11.8 \mathrm{~km}$ (relative error $19 \%$ ), followed by a measurement point at $12.6 \mathrm{~km}$ (relative error of $\sim 40 \%$ ). Above that altitude the noise prevails. It is worth mentioning that the laser is operated at $9 \mathrm{~W}$. Increasing the power to its nominal $12 \mathrm{~W}$ value and longer averaging time could extend the measurements to the lower stratosphere when necessary.

Daytime lidar mixing ratio profile obtained on 9 April 2009 is shown in Fig. 13. The lidar data are averaged from 11:00 to 11:30 UTC with initial vertical averaging of $30 \mathrm{~m}$, increased to $75 \mathrm{~m}$ at $2.5 \mathrm{~km}$, and to $300 \mathrm{~m}$ above $4 \mathrm{~km}$. The profile is compared to an equipped-with 


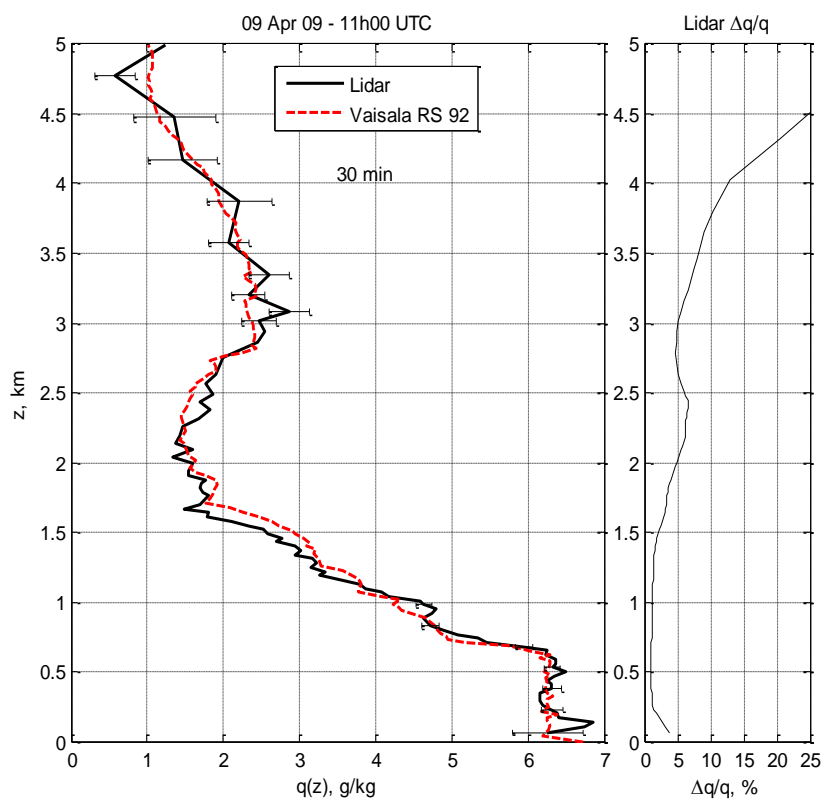

Fig. 13. Left : Daytime profiles of water vapor mixing ratio compared to Vaisala RS92 radiosonde launched on 9 April 2009 at 11:00 UTC; Right : Lidar statistical error profile.

Vaisala RS92 radiosonde launched at 11:00 UTC (13 h local time). The right plot shows the relative error profile of the lidar measurement derived from the signal statistics. The first lidar point is at $75 \mathrm{~m}$, and the measurement statistical error is about $5 \%$ due to the sky background in the water vapor channel. A well-mixed boundary layer defines an almost constant mixing ratio profile up to about $700 \mathrm{~m}$, captured by both instruments without big differences. Within the range from 700 to about $1.6 \mathrm{~km}$, the mixing ratio decreases to about $1.5 \mathrm{~g} \mathrm{~kg}^{-1}$. A small difference between the profiles is present and could be explained by variation of the water vapor field, which is typical for daytime conditions with strong vertical mixing. At above $1.6 \mathrm{~km}$ the lidar signal amplitude decreases (due to $z^{-2}$ ) and the statistical error increases despite the almost constant up to $2.5 \mathrm{~km}$ mixing ratio. Compared to nighttime measurements the statistical error is higher, mainly due to the presence of daytime sky background in the water vapor channel.

In order to explore the full potential of the lidar to resolve the spatiotemporal evolution of a water vapor field, time series with high temporal and spatial resolution were taken in favorable weather conditions while operating the laser at its nominal energy of $400 \mathrm{~mJ}(12 \mathrm{~W})$. As already mentioned, during regular operations the laser output energy is limited to $300 \mathrm{~mJ}(9 \mathrm{~W})$ to extend the lifetime of the flash lamps and to prevent damage of the optical elements of the laser and the transmitter. The lidar performance at reduced energy is sufficient for regular profiling, as demonstrated by the companion paper (Brocard et al., 2013), and the lidar can always be operated at nominal laser energy in case of special events.

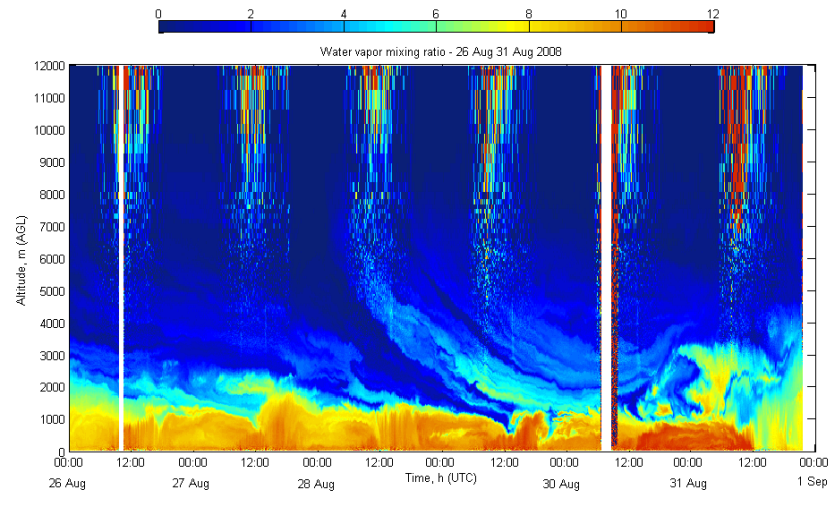

Fig. 14. Six-day time series of water vapor with $10 \mathrm{~min}$ time resolution. All data are shown, including data with a statistical error $>10 \%$. The noisy zones above $5000 \mathrm{~m}$ (around noon) mark the increase in statistical error due to the solar background during the daytime. The white zones mark data gaps.

Figure 14 presents time series with high temporal and spatial resolution taken from 26 August to 1 September. The temporal resolution of the data is $10 \mathrm{~min}$ and the vertical resolution is $30 \mathrm{~m}$ up to $4 \mathrm{~km}$; the vertical resolution increases to $75 \mathrm{~m}$ above this height. The white strips indicate an absence of data (lidar inauguration and rain). The high spatiotemporal resolution of the profiles allows visualizing wellknown - but difficult to observe with the classical methods - processes, such as the enhanced turbulent mixing in the boundary layer during the early afternoon, seen as alternating red and orange vertical strips with changing intensity around 12:00 UTC. Another interesting atmospheric phenomenon, besides the temporal evolution of the boundary layer, is the subsidence of dry air from high altitudes to the lower troposphere. The most pronounced subsidence during the observational period was recorded on 28 August and is probably the result of stratosphere-troposphere exchange. The fast temporal evolution and spatial displacement as seen from Fig. 14 can explain a great part of the lidar to sonde discrepancies observed in the previous examples.

\section{Summary and outlook}

A new Raman lidar designed for unattended, continuous measurement of vertical water vapor profiles for operational meteorology has been described. To attain daytime operation, the lidar uses narrow field-of-view (NFOV), narrowband (NB) configuration and a UV laser. A $15 \times$ beam expander ensures low beam divergence, essential for the NFOV design, and reduces the laser energy density to levels meeting eye safety regulations. The receiver consists of four $30 \mathrm{~cm}$ in diameter mirrors fiber-coupled to a grating polychromator. The detection is carried out by Hamamatsu metal dynode photomultipliers and a Licel transient recorder acquires the signals in analog and photon-counting mode. The need 
for range-dependent overlap corrections is eliminated by the careful design of the receiver, which eliminates the range dependence of the instrumental part of the lidar calibration constant, thus allowing data retrieval from the incomplete overlap region without the need for range (overlap) corrections. Additional fiber in one of the telescope mirrors collects the scattered light from the near range, thus extending the distance range down to $100 \mathrm{~m}$. The value of the temperature correction is reduced to levels around $1 \%$ by selection of the polychromator central wavelength and bandwidth. The optomechanical design of the lidar ensures long-term alignment stability and eliminates the need for frequent transmitterreceiver alignments. The unattended automated control of the lidar is carried out by two computes controlling the hardware and performing automated data treatment. After its installation in July 2007 and the initial tests, the lidar has been in regular operation since August 2008 at the main aerological station of the Swiss Meteorological Office (MeteoSwiss).

Since 2007, the lidar has shown annual technical availability between 65 and $90 \%$. More information on this is available in the companion paper (Brocard et al., 2013). The main technical problems encountered during the first three years of operation were related to the supporting equipment (cooling water chiller, air conditioning, roof hatch) or the laser. The technical unavailability due to the supporting equipment and some of the laser problems, namely those related to the internal cooling system, were resolved to a great extent. A persisting problem is the laser misalignment after flash-lamp replacement, caused by insufficient positioning accuracy of the oscillator and amplifier pumping chambers. Redesigning of the pumping chambers and their support, planned for the near future, are expected to resolve this problem.

The lidar was upgraded with a pure rotational Raman channel for temperature, aerosol backscatter and extinction measurements, which has been operational in test mode since 2009. The channel design and analysis of the data will be presented in a separated paper after completing the test period and initiation of regular operations.

Acknowledgements. The authors gratefully acknowledge the financial support of the Swiss National Foundation under grant 510021. The authors wish to recognize Ilya Serikov for his contribution to the development of the lidar system and Alexander Haefele for helpful comments on the manuscript. We also thank Adelina Simeonova for her help in preparing the manuscript.

Edited by: G. Ehret

\section{References}

Ansmann, A., Riebesell, M., Wandinger, U., Weitkamp, C., Voss, E., Lahmann, W., and Michaelis, W.: Combined Raman elasticbackscatter LIDAR for vertical profiling of moisture, aerosol extinction, backscatter, and LIDAR Ratio, Appl. Phys. B, 42, 1828, 1992.
Appituley, A., Wilson, K., Potma, C., Volten, H., and de Graaf, M.: Performance assessment and application of CAELI - A highperformance Raman lidar for diurnal profiling of Water Vapour, Aerosols and Clouds, Proceedings of the 8th International Symposium on Tropospheric Profiling, edited by: Apituley, A., Russchenberg, H. W. J., and Monna, W. A. A., ISBN 978-90-6960233-2 Delft, The Netherlands, S06-O10, October, 2009.

Arnold, D. L.: Severe deep moist convective storms: Forecasting and mitigation, Geography Compass, 2, 30-66, 2008.

Avila, G., Fernandez, J. M., Mate, B., Tejeda, G., and Montero, S.: Ro-vibrational Raman cross sections of water vapor in the $\mathrm{OH}$ stretching region, J. Mol. Spec., 196, 77-92, 1999.

Balin, I., Serikov, I., Bobrovnikov, S., Simeonov, V., Calpini, B., Arshynov, Y., and van den Bergh, H.: Simultaneous measurement of atmospheric temperature, humidity, and aerosol extinction and backscatter coefficients by a combined vibrational-purerotational Raman lidar, Appl. Phys. B, 79, 775-782, 2004.

Bösenberg, J.: Ground-based differential absorption lidar for water vapor and temperature profiling: methodology, Appl. Opt., 37, 3845-3860, 1998.

Bösenberg, J. and Linné, H.: Continuous ground-based water vapor profiling using DIAL, Reviewed and revised papers presented at 23 rd ILRC, 24-28 July, Nara, Japan, 679-683, 2006.

Brocard, E., Philippona, R., Haefele, A., Romanens, G. Mueller, A., Ruffieux, D., Simeonov, V., and Calpini, B.: Raman Lidar for Meteorological Observations, RALMO - Part 2: Validation of water vapor measurements, Atmos. Meas. Tech., 6, 1347-1358, doi:10.5194/amt-6-1347-2013 2013.

Browell, E., Ismail, S., and Grant, W.: Differential absorption lidar (DIAL) measurements from air and space, Appl. Phys. B, 67, 399-410, 1998.

Bruneau, D., Quaglia, P, Flamant, C., Meissonnier, M., and Pelon, J.: Airborne Lidar LEANDRE II for Water-Vapor Profiling in the Troposphere. I. System description, Appl. Opt., 40, 3450-3461, 2001.

Calpini, B., Ruffieux, D., Bettems, J.-M., Hug, C., Huguenin, P., Isaak, H.-P., Kaufmann, P., Maier, O., and Steiner, P.: Groundbased remote sensing profiling and numerical weather prediction model to manage nuclear power plants meteorological surveillance in Switzerland, Atmos. Meas. Tech., 4, 1617-1625, doi:10.5194/amt-4-1617-2011, 2011.

Cooney, J.: Remote Measurements of Atmospheric Water Vapor Profiles Usingthe Raman component of laser backscatter, J. Appl. Meteorology., 9, 182-184, 1970.

Cooney, J., Petri, K., and Salik, A.: Measurements of high resolution atmospheric water vapor profiles by use of a solar blind Raman lidar, Appl. Opt., 24, 104-108, 1985.

Dinoev, T., Arshinov, Y., Bobrovnikov, S., Serikov, I., Calpini, B., van den Bergh, H., and Simeonov, V.: Meteorological water vapor Raman lidar - advances, Reviewed and revised papers presented at 23 rd ILRC, 24-28 July, Nara, Japan, 47-49, 2006.

Donovan, D., Whiteway, J., and Carswell, A.: Correction for nonlinear photon-counting effects in lidar systems, Appl. Opt., 32, 6742-6753, 1993.

Engelbart, D., Reichardt, J., Mattis, I., Wandinger, U., Klein, V., Meister, A., Hilber, B., and Jaenisch, V.: RAMSES - German meteorological service Raman lidar for atmospheric moisture measuring, Reviewed and revised papers presented at 23rd ILRC, 24-28 July, Nara, Japan, 683-686, 2006. 
Evans, K. D., Demoz, B., Cadirola, M., Melfi, H., Whiteman, D., Schwemmer, G., Starr, D., Schmidlin, F., Feltz, W., Tobin, D., and Gutman, S.: A new Raman water vapor lidar calibration technique and measurements in the vicinity of hurricane Bonnie, 20th International Laser Radar Conference, Vichy, France, July, 2000.

Fabry, C. and Buisson, H.: A study of the UV end of the solar spectrum, The Astrophysical Journal, LIV, 297-322, 1921.

Ferrare, R., Melfi, S. H., Whiteman, D. N., Evans, K. D., Schmidlin, F. J., and Starr, D. O'C.: A comparison of water vapor measurements made by Raman lidar and radiosondes, J. Atmos. Ocean. Tech., 12, 1177-1195, 1995.

Ferrare, R., Browell, E., Ismail, A., Kooi, A, Brasseur, L, Brackett, V, Clayton M., Barrick, J., Diskin, G.,. Goldsmith, J.,. Lesht, B., Podolske, J., Sachse, G., Schmidlin, F., Turner, D., Whiteman, D., Tobin, D., Miloshevich, L., Revercomb, H., Demoz, B., and di Girolamo, P.: Characterization of Upper-Troposphere Water Vapor Measurements during AFWEX Using LASE, J. Atmos. Ocean. Tech., 21, 1790-1808, 2004.

Goldsmith, J., Blair F. H., Bisson, S. E., and Turner, D. D.,: Turnkey Raman lidar for profiling atmospheric water vapor, clouds, and aerosols, Appl. Opt., 37, 4979-4990, 1998.

Ingle, J. D. and Crouch, S.: Pulse overlap effects on linearity and signal-to-noise ratio in photon counting systems, Anal. Chem., 44, 777-784, 1972.

Leblanc, T., McDermid, I. S., and Walsh, T. D.: Ground-based water vapor raman lidar measurements up to the upper troposphere and lower stratosphere for long-term monitoring, Atmos. Meas. Tech., 5, 17-36, doi:10.5194/amt-5-17-2012, 2012.

Liu, Z., Hunt, W., Vaughan, M., Hostetler, C., McGill, M., Powell, K., Winker, D., and Hu, Y.: Estimating random errors due to shot noise in backscatter lidar observations, Appl. Opt., 45, 4437-4447, 2006.

Measures, R. M.: Laser remote sensing: fundamentals and applications, Krieger publishing company, Florida, 225 pp., 1992.

Melfi, S. H.: Remote Measurements of the Atmosphere Using Raman Scattering, Appl. Opt., 11, 1605-1610, 1972.

Nash, J., Oakley, T., Vomel, H., and Wei, L.: WMO intercomparison of high quality radiosonde systems, Yangjiang, China, 12 July-3 August 2010, Tech. Rep. 107, World Meteorological Organization, WMO/TD No.1580, 2011.

Newsom, R., Turner, D., Mielke, B. Clayton, M., Ferrare, R., and Sivaraman, C.: Simultaneous analog and photon counting detection for Raman lidar, Appl. Opt., 48, 3903-3914, 2009.

Normand, C. W.: On instability from water vapour, Q. J. Roy. Meteorol. Soc., 64, 47-70, 1938.

Peppler, R. A.: Tropospheric Static Stability and Central North American Growing Season Rainfall, Mon. Weather Rev., 117, 1156-1180, 1989

Renaut, D., Pourny, J., and Capitini, R.: Daytime Raman-lidar measurements of water vapor, Opt. Lett., 5, 233-235, 1980.

Reichardt, J., Wandinger, U., Klein, V., Mattis, I., Hilber, B., and Begbie, R.: RAMSES: German Meteorological Service autonomous Raman lidar for water vapor, temperature, aerosol, and cloud measurements, Appl. Opt., 51, 8111-8131, 2012.

Schneider, M. and Hase, F.: Ground-based FTIR water vapour profile analyses, Atmos. Meas. Tech., 2, 609-619, doi:10.5194/amt2-609-2009, 2009.
Sherlock, V., Garnier, A., Hauchecorne, A., and Keckhut, P.: Implementation and validation of a Raman lidar measurement of middle and upper tropospheric water vapor, Appl. Opt., 38, 58385850, 1999.

Simeonov, V., Larcheveque, G., Quaglia, P., van den Bergh, H., and Calpini, B.: Influence of the photomultiplier tube spatial uniformity on lidar signals, Appl. Opt., 38, 5186-5190, 1999.

Simeonov, V., Dinoev, T., Calpini, B., Bobrovnikov, S., Arshinov, Y., Ristori, P., van den Bergh, H., and Parlange, M.: A Raman lidar as operational tool for water vapor profiling in the Swiss meteorological office, ILRC 25, St. Petersbourgh, 1175-1178, 2010.

Sinha, A. and Harries, E. J.: Water vapour and greenhouse trapping: The role of far infrared absorption, Geophys. Res. Lett., 22, 2147-2150, 1995.

Solheim, F.: Radiometric profiling of temperature, water vapor and cloud liquid water using various inversion methods, Radio Sci., 33, 393-404, 1998.

Turner, D. and Goldsmith, J.: Twenty-Four-Hour Raman Lidar Water Vapor Measurements during the Atmospheric Radiation Measurement Program's 1996 and 1997 Water Vapor Intensive Observation Periods, J. Atmos. Ocean. Tech., 16, 1062-1076, 1999.

Turner, D. D., Feltz, W. F., and Ferrare, R. A.: Continuous water vapor profiles from operational ground-based active and passive remote sensors, B. Am. Meteorol. Soc., 81, 1301-1318, 2000.

Turner, D., Ferrare, R., Heilman, C., Brasseur, L., Feltz, W., and Tooman, T.: Automated retrievals of water vapor and arerosol profiles from an operational Raman lidar, J. Atmos. Ocean. Tech., 19, 37-50, 2002.

Vaughan, G., Wareing, D. P., Thomas, L., and Mitev, V.: Humidity measurements in the free troposphere using Raman backscatter, Q. J. Roy. Meteorol. Soc., 114, 1471-1484, 1988.

Vömel, H., Fujiwara, M., Shiotani, M., Hasebe, F., Oltmans, S. J., and Barnes, J. E.: The behavior of the SnowWhite chilled-mirror hygrometer in extremely dry conditions , J. Atmos. Ocean. Tech., 20, 1560-1567, 2003.

Whiteman, D. N.: Raman lidar system for the measurement of water vapor and aerosols in the Earth's atmosphere, Appl. Opt., 31, 3068-3082, 1992.

Whiteman, D. N.: Examination of the traditional Raman lidar technique. I. Evaluating the temperature-dependent lidar equations, Appl. Opt., 42, 2571-2592, 2003.

Whiteman, D. N., Schwemmer, G., Berkoff, T., Plotkin, H., RamosIzquierdo, L., and Pappalardo, G.: Performance modeling of an airborne Raman water-vapor lidar, Appl. Opt., 40, 375-390, 2001.

Whiteman, D. N., Cadirola, M., Venable, D., Calhoun, M., Miloshevich, L., Vermeesch, K., Twigg, L., Dirisu, A., Hurst, D., Hall, E., Jordan, A., and Vömel, H.: Correction technique for Raman water vapor lidar signal-dependent bias and suitability for water vapor trend monitoring in the upper troposphere, Atmos. Meas. Tech., 5, 2893-2916, doi:10.5194/amt-5-2893-2012, 2012.

Wirth, M., Fix, A., Mahnke, P., Schwarzer, H., Schrandt, F., and Ehret, G.: The airborne multi-wavelength water vapor differential absorption lidar WALES: system design and performance, Appl. Phys. B, 96, 201-213, 2009.

Wulfmeyer, V.: Ground-based differential absorption lidar for water-vapor and temperature profiling: development and specifications of a high-performance laser transmitter, Appl. Opt., 37, 
3804-3824, 1998.

Wulfmeyer, V. and Bosenberg, J.:Ground-based differential absorption lidar for water-vapor profiling: assessment of accuracy, resolution, and meteorological applications, Appl. Opt., 37, 38253844, 1998.
Wulfmeyer, V., Behrendt, A., Bauer, H., Kottmeier, C.,Corsmeier, U., Blyth, A., Craig, G., Schumann, U., Hagen, M., Crewell ,S., Di Girolamo, P., Flamant, C., Miller, M., Montani, A., Mobbs, S., Richard, E., Rotach, M., Arpagaus, M., Russchenberg, H.,Schlüssel, P., König, M., Gärtner, V., Steinacker, R., Dorninger, M., Turner, D., Weckwerth, T., Hense, A., and Simmer, C.: The Convective and Orographically Induced Precipitation Study, B. Am. Meteorol. Soc., 89, 1477-1486, 2008. 